\title{
Endosomal sorting and c-Cbl targeting of paxillin to autophagosomes regulate cell-matrix adhesion turnover in human breast cancer cells
}

\author{
Chia-Hao Chang ${ }^{1,2}$, Krikor Bijian ${ }^{1,2}$, Dinghong Qiu ${ }^{1,2}$, Jie Su ${ }^{1,2}$, Amine Saad ${ }^{1,2}$, Michael \\ S. Dahabieh", ${ }^{1,2}$ Wilson H. Miller Jr., ${ }^{1,2}$, Moulay A. Alaoui-Jamali',2
${ }^{1}$ Department of Medicine, Lady Davis Institute for Medical Research and Segal Cancer Center, SMBD Jewish General Hospital, Faculty of Medicine, McGill University, Montreal, Canada
${ }^{2}$ Department of Oncology, Lady Davis Institute for Medical Research and Segal Cancer Center, SMBD Jewish General Hospital, Faculty of Medicine, McGill University, Montreal, Canada

Correspondence to: Moulay A. Alaoui-Jamali, email: moulay.alaoui-jamali@mcgill.ca

Keywords: paxillin, focal adhesion dynamics, Rab7-GTPase, c-Cbl, autophagy

Received: January 12, 2017 Accepted: March 01, 2017 Published: March 10, 2017

Copyright: Chang et al. This is an open-access article distributed under the terms of the Creative Commons Attribution License (CC-BY), which permits unrestricted use, distribution, and reproduction in any medium, provided the original author and source are credited.

\section{ABSTRACT}

Post-translational mechanisms regulating cell-matrix adhesion turnover during cell locomotion are not fully elucidated. In this study, we uncovered an essential role of Y118 site-specific tyrosine phosphorylation of paxillin, an adapter protein of focal adhesion complexes, in paxillin recruitment to autophagosomes to trigger turnover of peripheral focal adhesions in human breast cancer cells. We demonstrate that the Rab-7 GTPase is a key upstream regulator of late endosomal sorting of tyrosine118-phosphorylated paxillin, which is subsequently recruited to autophagosomes via the cargo receptor c-Cbl. Essentially, this recruitment involves a direct and selective interaction between Y118-phospho-paxillin, c-Cbl, and LC3 and is independent from c-Cbl E3 ubiquitin ligase activity. Interference with the Rab7-paxillin-autophagy regulatory network using genetic and pharmacological approaches greatly impacted focal adhesion stability, cell locomotion and progression to metastasis using a panel of human breast cancer cells. Together, these results provide novel insights into the requirement of phospho-site specific post-translational mechanism of paxillin for autophagy targeting to regulate cell-matrix adhesion turnover and cell locomotion in breast cancer cells.

\section{INTRODUCTION}

Cell migration is a physiological process fundamental for embryonic development, immune and inflammatory responses, wound healing, and tissue homeostasis [1,2]. Aberrant cell migration has been associated with several pathologies including rare inherent diseases such periventricular heterotopia [3], BaraitserWinter syndrome [4] and more common diseases such as cancer progression to metastasis [5].

In general, motile cells exhibit finger-like protrusions (e.g. lamellipodia, filopodia) of the plasma membrane that are stabilized by the formation of focal adhesions (FAs). The synchronous cycle of FA assembly/disassembly are essential for cell locomotion [6] and require the integration of multiple signals from extracellular matrixreceptor interactions, cell cytoskeleton and binding to intracellular proteins primarily those involved in endocytic trafficking, in particular members of the Rab GTPase family involved in early endosome development [7-11], many of which are amplified in invasive cancers and have been associated with enhanced cancer cell invasiveness [12-14]. However, there remains a fundamental gap in understanding the molecular mechanisms by which Rab GTPases that are involved in late endosomal maturation regulate FA turnover, with a particular focus on FA posttranslational modifications that trigger these events.

In this study, we report a novel role for the late endosomal protein Rab7 GTPase in the regulation of the selective recruitment of tyrosine 118 (Y118)phosphorylated paxillin, but not Y31-phospho-paxillin to autophagosomes via its interaction with $\mathrm{c}-\mathrm{Cbl}$, which serves as a cargo receptor independently of its E3 ubiquitin ligase activity, in human breast cancer cells. This novel Rab7-mediated turnover of 118Y-p-paxillin was inhibited upon Atg12 downregulation, thereby reinforcing the implication of the autophagic pathway. This regulatory axis was not seen with other FA proteins 
such as FAK and was not affected by Src manipulation. Although autophagy-mediated FA turnover has recently been identified in mouse mammary 4T1 cells [15], studies describing this mechanism in human cells have yet to be elucidated. Therefore, these novel interactions which are required for the motility and invasiveness of human breast cancer cells, may serve as an effective approach for targeting the progression of this disease.

\section{RESULTS}

\section{Rab7 regulates FA turnover, cancer cell locomotion and progression to metastasis}

To understand the role of the Rab7 GTPase in cancer cell migration, we first investigated its impact on FA turnover using two human breast cancer cell lines with intrinsic invasive properties, MDA231-M2 and BT-20 cells, and their matched counterparts where Rab7 was stably knockdown by shRNA (Figure 1A). Time-lapse confocal imaging in BT-20 cells expressing GFP-tagged paxillin revealed slower FA disassembly and persistence of FAs in Rab7-silenced cells compared to control cells (Figure 1B, left and quantification in the right panel). A similar observation was made using the nocodazolebased assay to enable transient synchronization of FA disassembly (revealed by an enrichment of FA formation as the result of exposure to nocodazole for 2 hours followed by FA disassembly and recovery after nocodazole washout [16]. Under this condition, maximal FA disassembly was seen at 30 min post-nocodazole washout, followed by reassembly of FAs, which was obvious from $30 \mathrm{~min}$ to $1 \mathrm{~h}$. In comparison to control cells, Rab7-silenced cells reveal slower turnover of $118 \mathrm{Y}$-p-paxillin, especially at $15 \mathrm{~min}$ after nocodazole washout (Supplementary Figure 1).

Investigation of cell migration confirmed that in MDA231-M2 cells where Rab7 was downregulated, cell locomotion was significantly compromised compared to control cells (Figure 1C, 1D and Supplementary Video 1). Similar results were seen in BT-20 cells. Noteworthy, reduced cell locomotion was not mediated by changes in cell proliferation as no difference in cell growth was seen between Rab7-shRNA and their matched control cells (Supplementary Figure 2).

To further confirm the correlation between these in vitro observations and cancer progression in vivo, we investigated the impact of Rab7 down-regulation on cancer cell progression to metastasis using MDA231-M2 cells expressing control shNT or Rab7 shRNA implanted orthotopically into the mammary fat pad of SCID mice. After 40 days observation, a significant inhibition in the number of lung metastases was seen with the Rab7silenced cells compared to control cells (Figure 1E, top). Quantification confirmed that the number of lung metastases were significantly decreased in the absence of
Rab7 (Figure 1E, bottom), despite having similar primary tumors weights.

\section{Knockdown of Rab7 promotes paxillin enrichment in cytoplasmic puncta}

To further investigate the relationship between Rab7 expression and FA dynamics we examined the protein levels of various FA components in BT-20 cells under conditions where Rab7 is downregulated. As such, we observed increasing levels of phosphorylated paxillin and Src in Rab7 shRNA cells, compared to control cells (Figure 2A). Other FA-associated proteins such as FAK remained unchanged. Furthermore, we observed pronounced relocation of $118 \mathrm{Y}$-p-paxillin to distinctive intracellular puncta in cells where Rab7 was downregulated, while 118Y-p-paxillin predominantly localized to adhesion sites in control cells (Figure 2B, top and quantified in the bottom panel).

To investigate if Rab7-GTPase activity was essential for paxillin relocalization into these cytoplasmic puncta, we expressed control (GFP-C1), wild-type Rab7 (GFPRab7) or a Rab7-GTPase defective mutant (GFP-Rab7T22N) [17] in control and Rab7-silenced cells (Figure 2C). As shown in Figure 2D (solid arrows), in Rab7-deficient cells where the expression of wild type Rab7 was restored, the expression of $118 \mathrm{Y}$-p-paxillin in FAs was rescued. However, expression of the dominant negative GFPRab7-T22N resulted in the reappearance of perinuclear $118 Y$-p-paxillin puncta even in control cells expressing endogenous Rab7 (Figure 2D, left and quantification in the right panel). These findings demonstrate that interfering with Rab7 or its GTPase activity prevented the trafficking of phosphorylated paxillin.

\section{Y-p-paxillin accumulates in autophagolysosomes in Rab7-depleted cells}

Rab7 plays an essential role in the maturation of late autophagic vacuoles $[18,19]$. Therefore, we investigated whether 118Y-p-paxillin was arrested in these late autophagic vacuoles. To do so, we first used chloroquine (CQ), a small molecule that accumulates in autophagic vesicles to prevent fusion of autophagosomes to lysosomes [20]. As shown in Figure 3A, exposure of cells to CQ for $24 \mathrm{~h}$ significantly led to the accumulation of LC3-II, which was similar to what we observed in cells expressing Rab7 shRNA (Figure 3A). Moreover, both CQ and Rab7 shRNA induced LC3 puncta formation, as compared to respective controls (Figure 3B), which indicated that both approaches cause late stage autophagy blockade. To further decipher the localization of these $118 \mathrm{Y}$-p-paxillin puncta, co-staining of 118Y-p-paxillin with LAMP-1 (lysosome marker) and LC3 (autophagy marker) was performed. As shown in Figure 3C, the puncta observed upon Rab7 knockdown 
or CQ treatment were indicative of an accumulation in autophagolysosomes (Figure 3C). These findings were further supported by our density gradient centrifugation studies, which consisted of enriching various cellular compartments including autophagosomes. Although $118 Y$-p-paxillin accumulation in autophagosomes is clearly visible in both cell lines, increased accumulation is observed in shRab7 autophagosomes since trafficking is compromised in this condition (Figure 3D). Furthermore, monitoring FA dynamics in live cells revealed significantly reduced FA disassembly rates and prolonged FA duration at FA site in CQ-treated cells, as compared to controls (Supplementary Figure 3). This specific localization of 118Y-p-paxillin with LC3 in autophagosomal puncta upon
CQ treatment was not exclusive to BT-20 cells, as it was also observed in CQ-treated MDA-MB-231 and MCF-7 cells (Figure 3E).

\section{Rab7 regulates 118Y-p-paxillin turnover through the autophagy pathway rather than endosomal degradation}

Considering that Rab7 can play a role in both endosomal and autophagic pathways which converge at late autophagic vacuoles, we seeked to identify which of these pathways is primarily responsible for $118 \mathrm{Y}$-p-paxillin trafficking to autophagosomes. Therefore, we silenced either Rab5 (endosomal upstream regulator) or Atg12
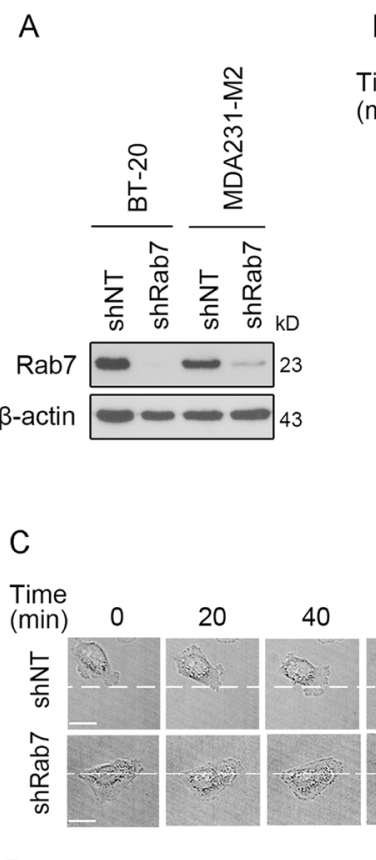

D
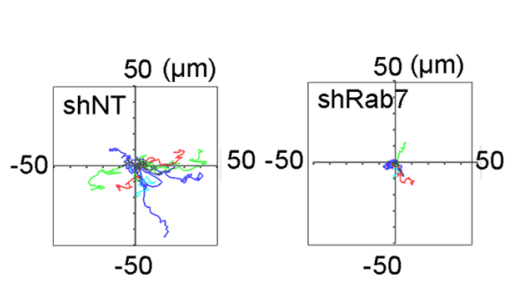

\section{B}
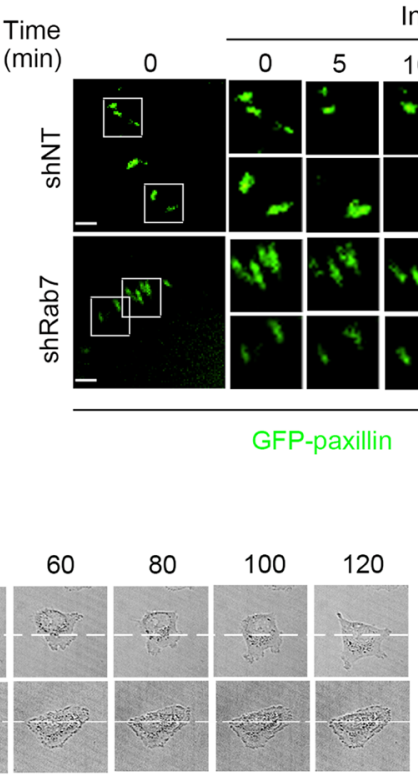

Inset

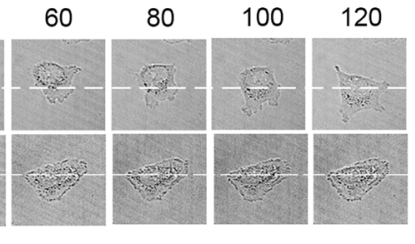

$\mathrm{E}$
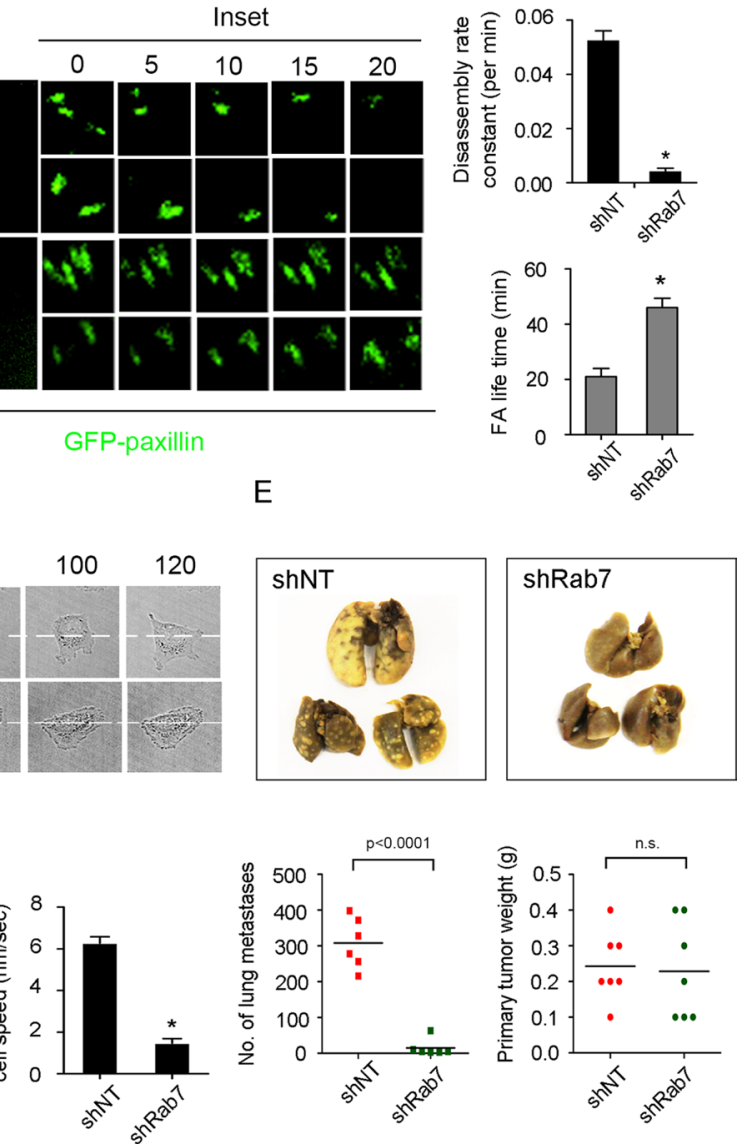

Figure 1: Knockdown of Rab7 decreases focal adhesion turnover, cell migration and progression to metastasis. (A) MDA231-M2 and BT-20 cells were lysed and immunoblotted with Rab7 and $\beta$-actin antibodies. $\beta$-actin was used as an internal control. (B) Left: Serum- starved BT-20 cells expressing non-targeted shRNA (shNT) and Rab7 shRNA (shRab7) were transfected with GFP-paxillin for $24 \mathrm{~h}$ and focal adhesion (FA) turnover was analyzed by time-lapse spinning disc microscopy with $2 \mu \mathrm{m}$ scale bar upon $20 \mathrm{ng} / \mathrm{ml}$ EGF stimulation. Higher-magnification images of the inserts are shown indicating positions of paxillin-containing FAs. Right: Quantification of FA disassembly and FA duration of shNT- and shRab7-expressing cells. Data are presented as mean \pm SEM $\left({ }^{*} p<0.05\right.$, $n=53$ FAs in shNT and $n=62$ FAs in shRab7 groups from 10 single cells). (C) Serum-starved shNT- and shRab7-MDA-231-M2 cells were stimulated with $20 \mathrm{ng} / \mathrm{ml}$ EGF and then cell motility monitored by time-lapse spinning disc microscopy. Scale bar, $20 \mu \mathrm{m}$. (D) Left: The paths of single MDA-231-M2 of shNT and shRab7 were tracked for 2 hours at a rate of 1 frame per 7.5 minutes. 15 tracks of shNT- and shRab7-expressing cells were plotted in different colors, respectively. Right: Speed quantification of MDA-231-M2 cells expressing shNT or shRab7 (mean \pm SEM, $n=15$ cells, $* p<0.05$ ) (E) Top, Graphs show the lung with metastatic nodules from the mice implanted with shNT or shRab7 MDA231-M2 cells. Bottom, quantification of the mean number of lung metastasis and the weight of primary tumor in mammary fat pad (mean \pm SEM, $n=6$ SCID mice, $\left.{ }^{*} p<0.05\right)$. 
(autophagic upstream regulator) using siRNA (Figure 4A) and then monitored $118 \mathrm{Y}$-p-paxillin puncta staining. As shown in Figure 4B, the 118Y-p-paxillin puncta staining could be rescued in Rab7-silenced cells after knocking down Atg12, but not Rab5. In addition, knockdown of Atg12 resulted in the enhancement of focal adhesion structures both in control and Rab7-silenced cells. This 118Y-p-paxillin enhancement in Atg12-silenced cells was further confirmed by immunoblotting (Figure 4C). To further confirm the dependence of FA turnover on the autophagic pathway, we monitored FA dynamics in Atg12knockdown cells expressing GFP-paxillin. As expected, Atg12 downregulation significantly decreased the rate of paxillin disassembly (Figure 4D), further reinforcing the implication of the autophagic pathway in Rab7-mediated turnover of $118 Y$-p-paxillin.

\section{Phosphorylation of the Y118-residue of paxillin is exclusively required for its targeting to autophagosomes and for autophagy-mediated FA turnover}

To establish the importance of paxillin posttranslational tyrosine modifications necessary for Rab7mediated autophagosomal targeting, we investigated the two tyrosine residues previously established to be

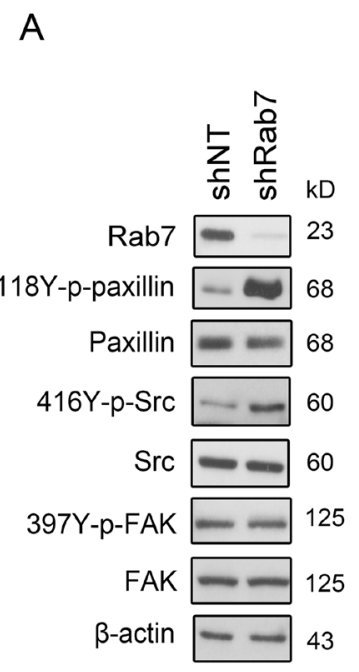

B
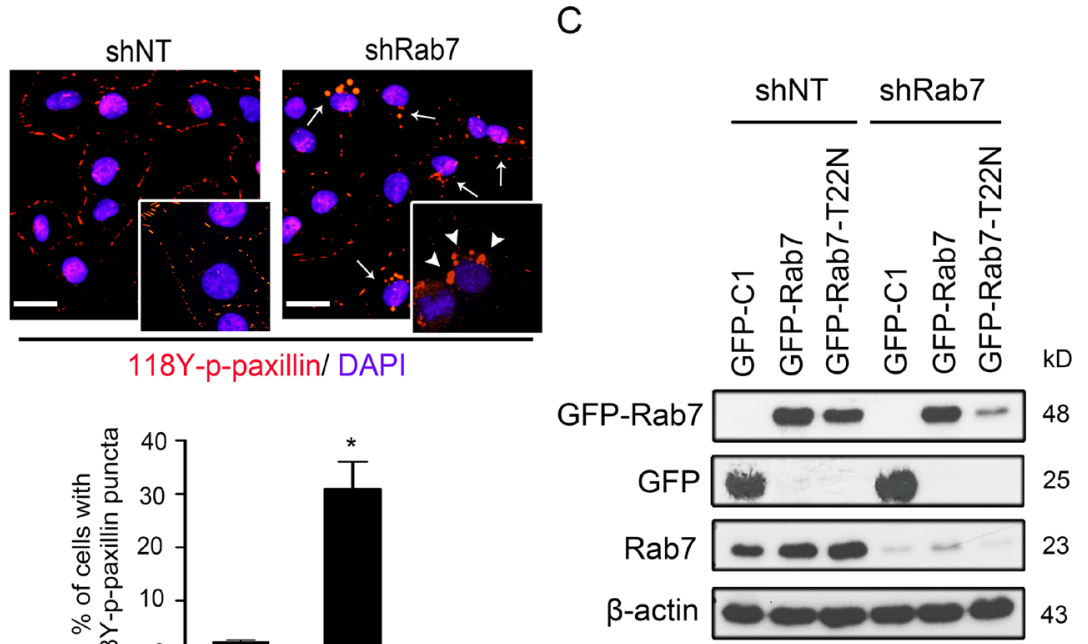

D

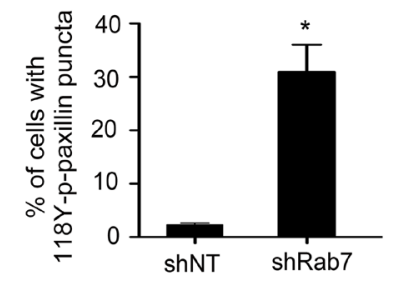

$\operatorname{shNT}$
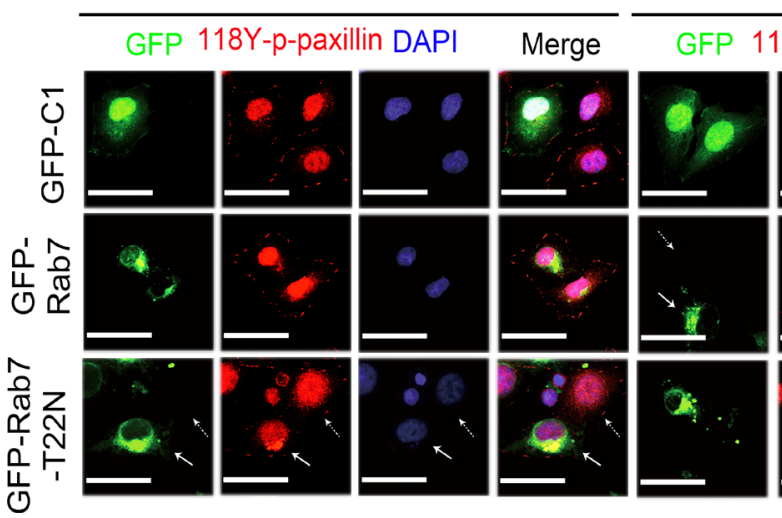

shRab7
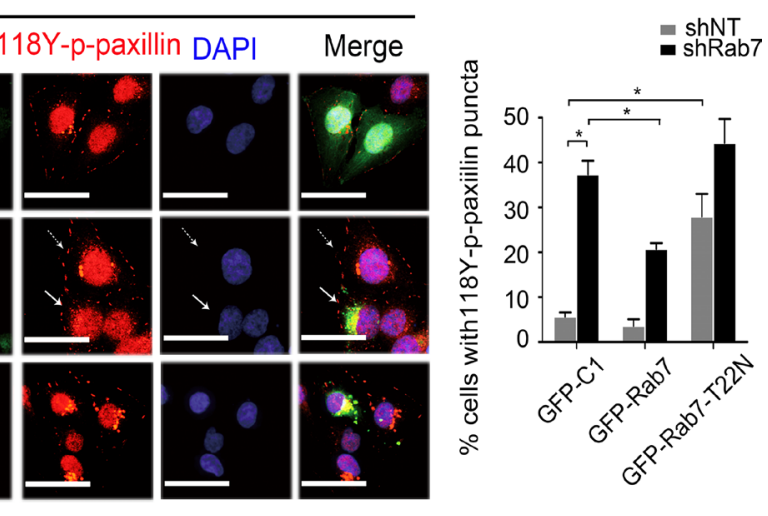

Figure 2: Rab7 and its GTPase activity are required for paxillin accumulation into cytosolic puncta. (A) Lysates from shNT or shRab7-expressing BT-20 cells were immunoblotted with antibodies against Rab7, LC3B, 118Y-p-paxillin, paxillin, 397Y-pFAK, FAK416Y-p-Src, Src and $\beta$-actin as an internal control. (B) Top: shNT and shRab7 transfected BT-20 cells were fixed and stained with anti-118Y-p-paxillin antibody (red) and with DAPI (blue). Solid arrows identify cells with 118Y-p-paxillin puncta. Arrowheads in inserts (65x magnification) indicate actual 118Y-p-paxillin puncta. Bottom: percentage of cells with 118Y-p-paxillin puncta. Data are presented as mean \pm SEM $\left({ }^{*} p<0.05, n=3\right)$. (C and D) BT-20 cells expressing shNT and shRab7 plasmids and their matched cells rescued with empty (GFP-C1), shRNA-resistant Rab7 (GFP-Rab7) or Rab7 with a point mutation (GFP-Rab7-T22N) plasmids, were lysed and immunoblotted with anti-GFP antibody (C) or were fixed and stained with anti-118Y-p-paxillin antibody (red) and with DAPI (blue). Scale bar, $20 \mu \mathrm{m}$. Solid arrows indicate the cell expressing GFP plasmids and dashed arrows indicate cells without expressing GFP plasmids $(\mathrm{D}$, left). ( $\mathrm{D}$, right) Graph shows the quantification of percentage of cells with $118 \mathrm{Y}$-p-paxillin in intracellular puncta (determined using lower magnification images $(20 \times))$. Data are presented as mean $\pm \operatorname{SEM}(* P<0.05, n=3)$ 
A

B

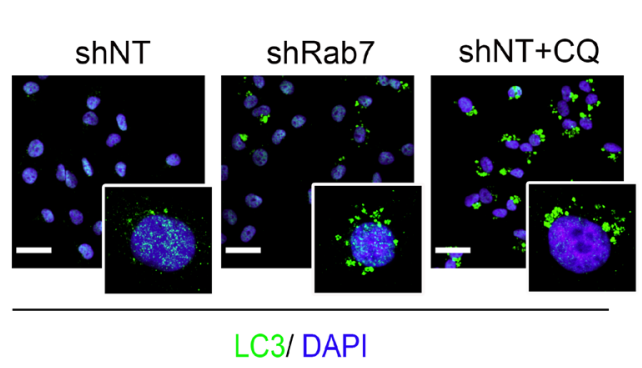

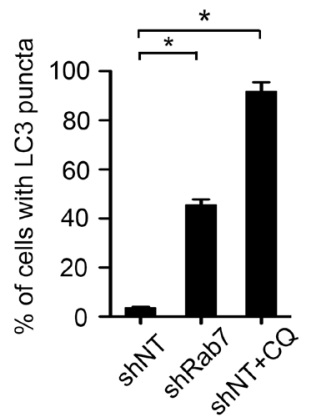

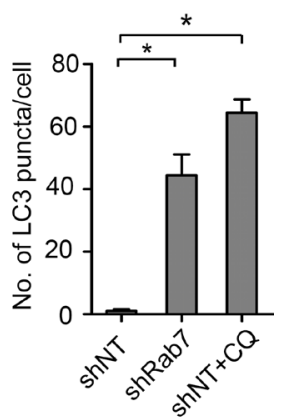

C

$\mathrm{D}$
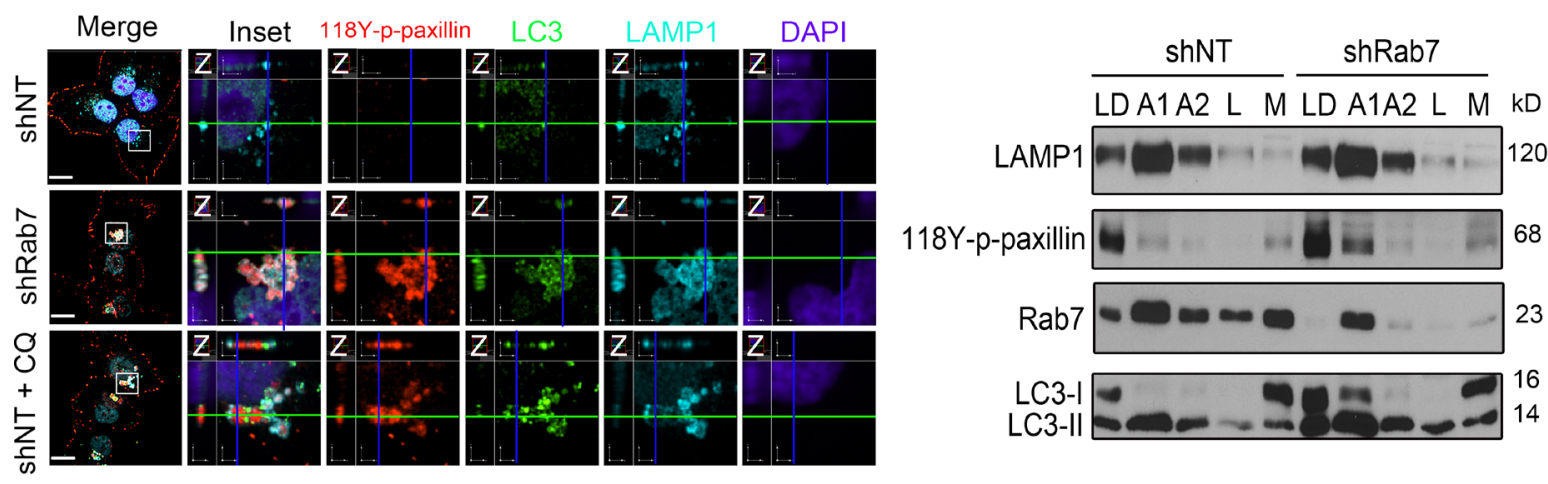

$\mathrm{E}$

Untreated

$C Q$

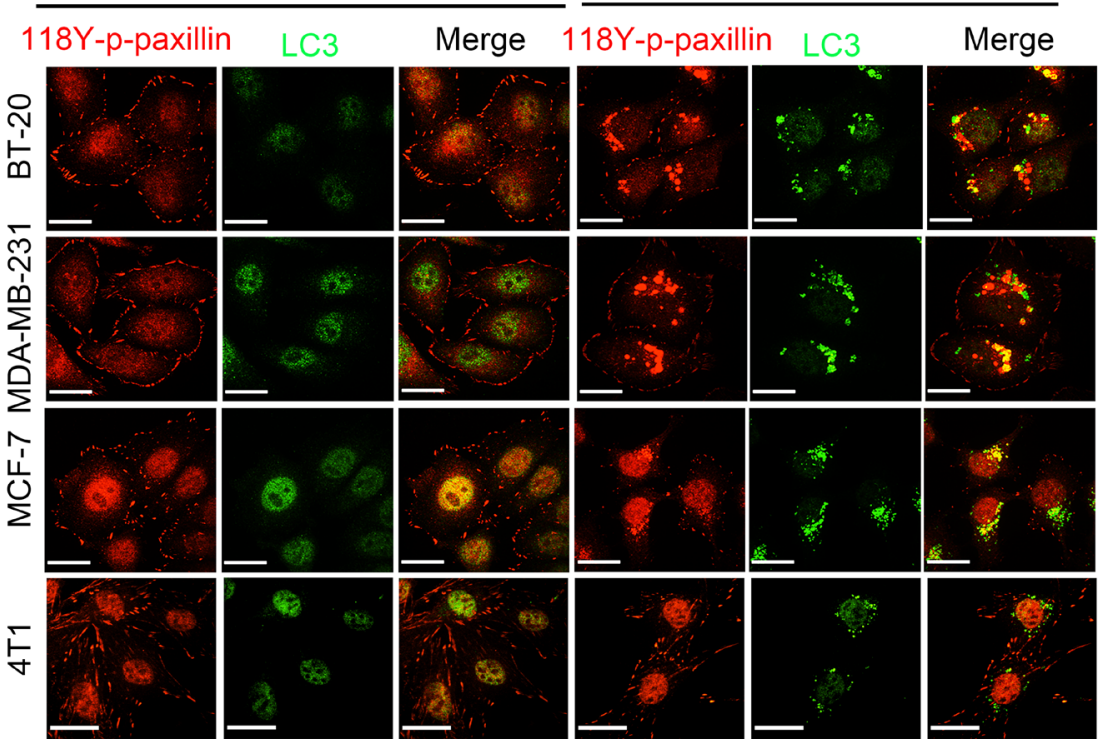

Figure 3: Knockdown Rab7 mimics the effect of chloroquine to localize paxillin into autophagolysosomes. (A-C) Control (shNT), Rab7-silenced (shRab7) and control treated with $20 \mu \mathrm{M}$ chloroquine (CQ) for $24 \mathrm{~h}$ (shNT+CQ) BT-20 cells lysed and immunoblotted with antibodies against Rab7, LC3B and $\beta$-actin (internal control) (A), fixed and stained with anti-LC3 antibody (green) and with DAPI (blue) with $20 \mu \mathrm{m}$ scale bar left (insert 63X) and quantification on the right panel showed percentage of cells with LC3 puncta and average \# of LC3 puncta/cell $(N=15)(\mathrm{B})$. Data are presented as mean $\left.\pm \operatorname{SEM}\left({ }^{*} p<0.05, n=6\right)\right)$ or further co-stained with anti-118Y-p-paxillin antibody (red), anti-LC3B antibody (green), anti-LAMP-1 antibody (cyan) and with DAPI (blue) with $20 \mu \mathrm{m}$ scale bar (C). Enlargements and cross-sections of the confocal-z-planes of the boxed regions are also shown indicating association of 118Y-ppaxillin, LC3B and LAMP-1. (D) Lysed shNT and shRab7-expressing BT-20 cells were subjected to nycodenze gradient centrifugation, then analyzed by immunoblotting using anti-LAMP1, anti-118Y-p-paxillin, anti-Rab7 and anti-LC3 antibodies. LD is the loading control, $\mathrm{A} 1$ and $\mathrm{A} 2$ are autophagosome-related fractions, $\mathrm{L}$ is the lysosomal fraction and $\mathrm{M}$ is the mitochondrial fraction. (E) MDA-MB-231, BT-20 and MCF-7 cells were treated either with PBS (untreated) or CQ for $24 \mathrm{~h}$, then fixed and stained with anti-118Y-p-paxillin or anti-416Y-pSrc antibodies (red) and anti-LC3 antibody (green). Scale bar, $20 \mu \mathrm{m}$. 
phosphorylated in dynamic focal adhesions [21], namely Tyr 31 and Tyr118. First we investigated whether nonphosphorylated paxillin or 31Y-p-paxillin can also accumulate in intracellular puncta similar to $118 \mathrm{Y}-\mathrm{p}-$ paxillin in Rab7 knockdown cells. Immunocytochemistry results supported that knockdown of Rab7 only caused accumulation of $118 \mathrm{Y}$-p-paxillin into puncta, whereas non-phosphorylated paxillin and 31Y-p-paxillin did not (Figure 5A). Next, we expressed EGFP-plasmids containing WT, Y31F, Y118F and Y31F/Y118F-paxillin constructs in BT20 cells (Figure 5B) and then monitored GFP-expression along with LAMP-1 and LC3B in

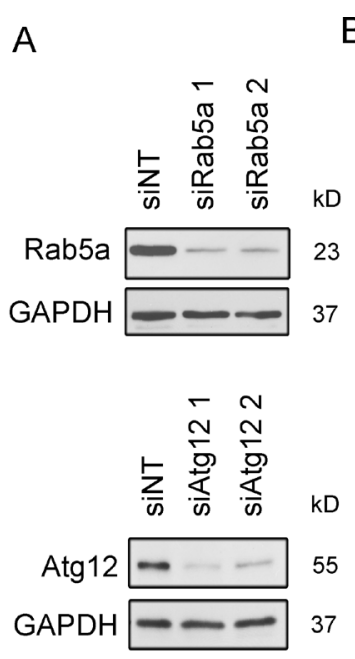

B

C
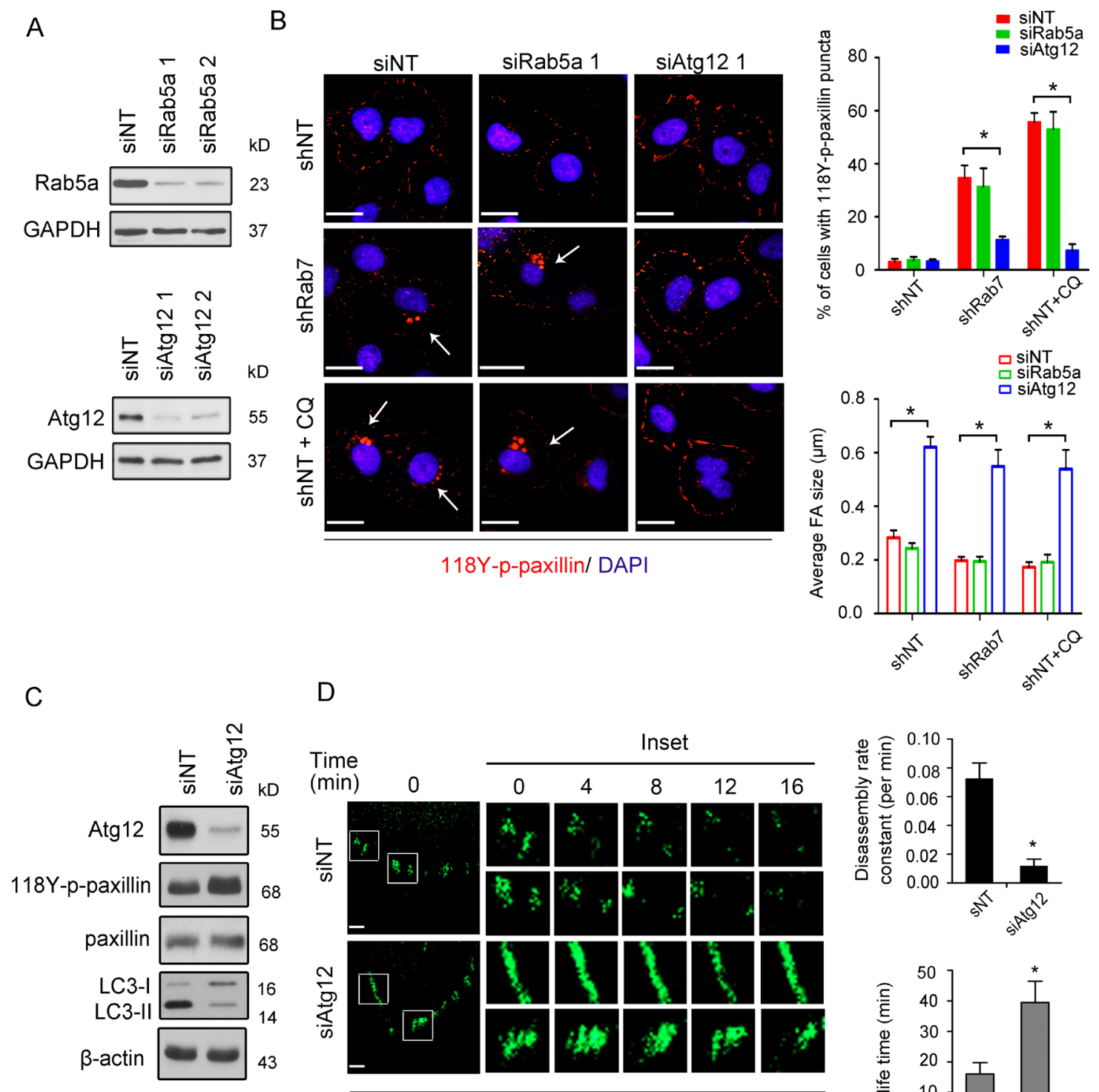

D
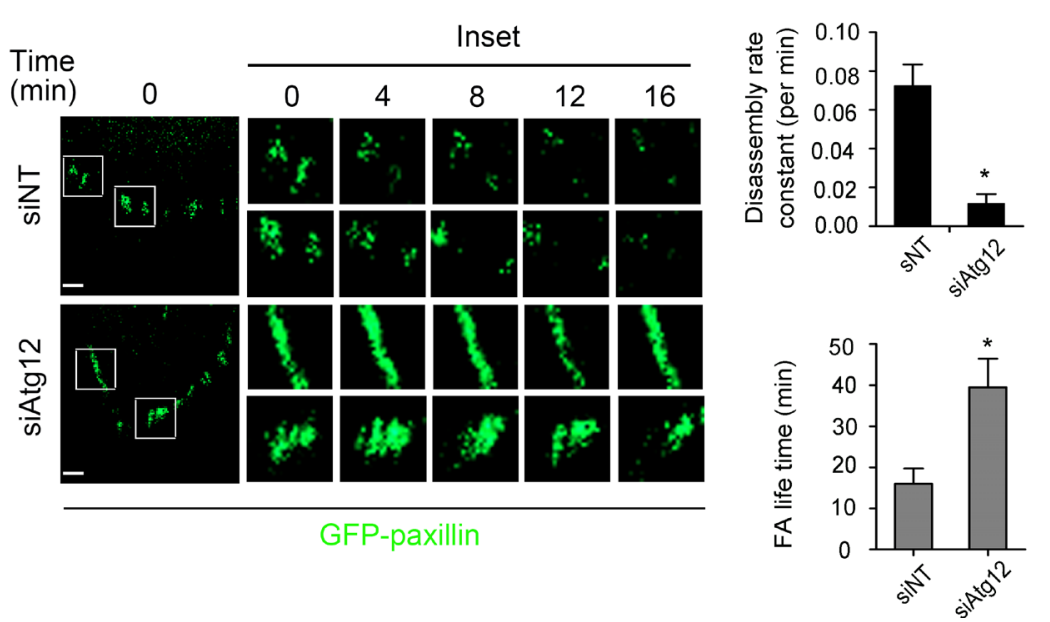

Figure 4: The autophagic pathway regulates Rab7-mediated paxillin turnover. (A) BT-20 cells were transiently transfected with $100 \mathrm{nM}$ non-targeted (siNT), Rab5a (siRab5) or Atg12 (siAtg12) siRNA for $48 \mathrm{~h}$ and total protein was extracted then immunoblotted with antibodies against Rab5a, Atg12 and anti-GAPDH as an internal control. (B) Left, shNT, shRab7 and shNT treated with CQ (shNT+CQ) BT-20 cells were respectively transfected with non-targeted, Rab5a or Atg12 siRNA for $48 \mathrm{~h}$ and stained with anti-118Y-p-paxillin antibody (red) and DAPI (blue). Arrows indicate the cells with 118Y-p-paxillin puncta. Scale bar, $20 \mu \mathrm{m}$. Right top, quantification of the percentage of cells with $118 \mathrm{Y}$-p-paxillin puncta. Data are presented as mean $\pm \mathrm{SEM}\left({ }^{*} p<0.05, n=3\right)$. Right bottom, quantification of average of FA size. Data are presented as mean $\pm \operatorname{SEM}\left({ }^{*} p<0.05, n=10\right.$ cells) $(\mathbf{C})$ shNT BT-20 cells were transfected with either $100 \mathrm{nM}$ siNT or siAtg 12 for $48 \mathrm{~h}$, then immunoblotted with antibodies against Atg12, 118Y-p-paxiilin, paxillin, Rab7, LC3B and anti- $\beta$-actin used as an internal control. (D) Left: Serum-starved siNT or siAtg12 BT-20 cells transfected with GFP-paxillin for $24 \mathrm{~h}$ were plated on chamber slide, stimulated by $20 \mathrm{ng} / \mathrm{ml}$ EGF and then analyzed for FA turnover by time-lapse spinning disc microscopy. Scale bar, $2 \mu \mathrm{m}$. Highermagnification images of the inserts are also shown indicating positions of paxillin-containing FAs. Right: FAs disassembly and FA life time in siNT and siAtg12 cells were quantified (mean \pm SEM, $n=75$ FAs in siNT and 88 FAs in siAtg12 from 10 single cells, ${ }^{*} p<0.05$ ). 
cells where autophagy was inhibited either using Rab7 knockdown or CQ treatment. While cells expressing WT or Y31F-paxillin demonstrated similar puncta, especially at locations where LC3B and LAMP-1 colocalize, Y118F or $\mathrm{Y} 31 \mathrm{~F} / \mathrm{Y} 118 \mathrm{~F}$ constructs were absent from these puncta (Figure 5C, 5D), further supporting the importance of Y118 phosphorylation for autophagosome targeting and subsequent accumulation in autophagolysosomes.

\section{Y118-p-paxillin interacts with LC3 at FA sites}

In order to gain further insight into mechanisms of paxillin recruitment to autophagosomes, we co-transfected BT-20 cells with FLAG-paxillin and GFP-LC3, followed by immunoprecipitation of FLAG-paxillin. As shown in Figure 6A, we were able to co-immunoprecipitate GFPLC3 with FLAG-paxillin. Once again, this interaction
A

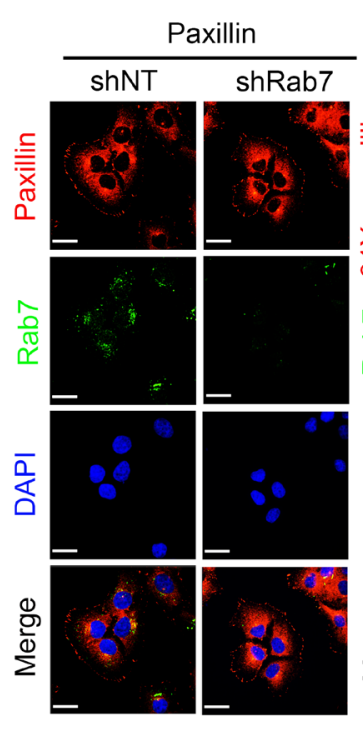

C

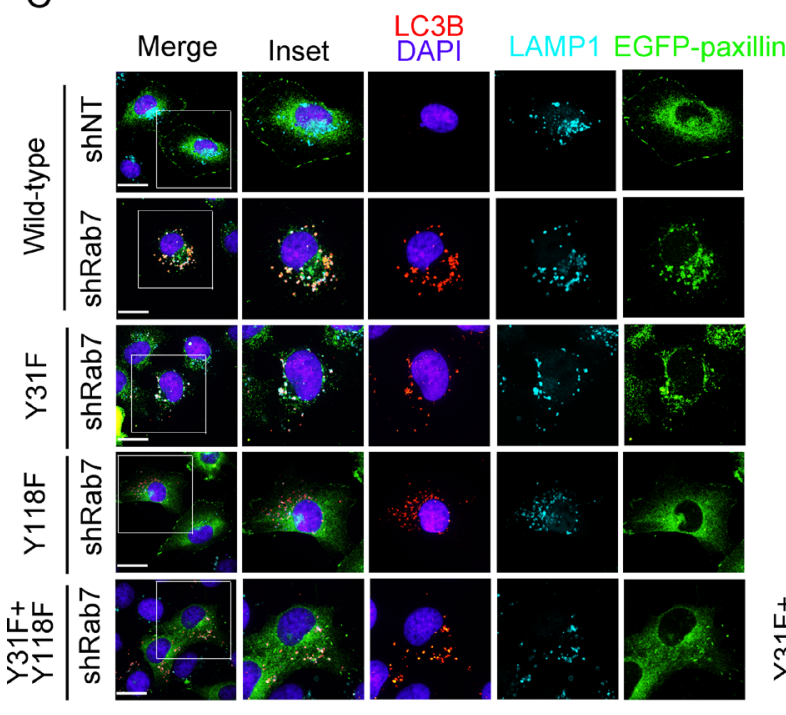

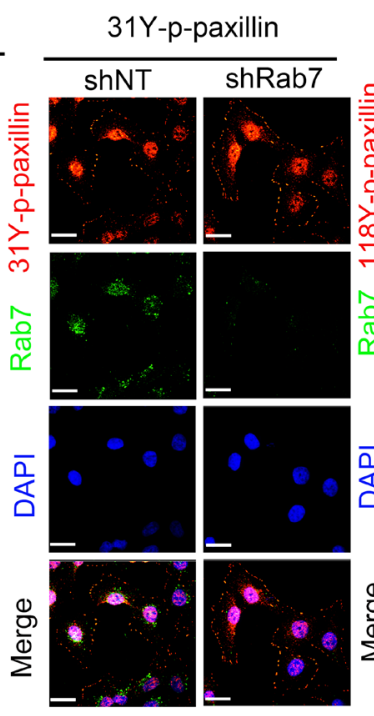

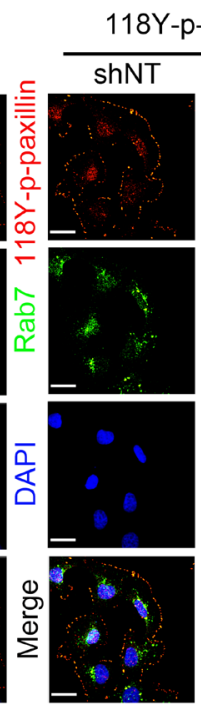

118Y-p-paxillin

shRab7
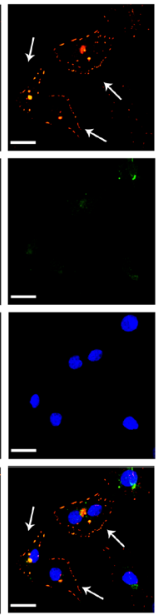

B
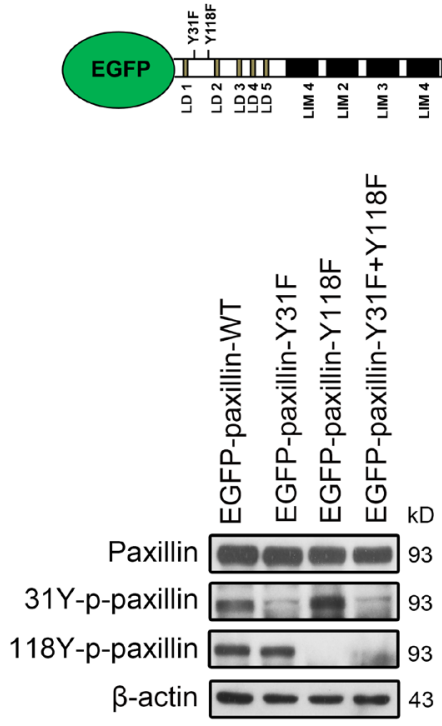

D

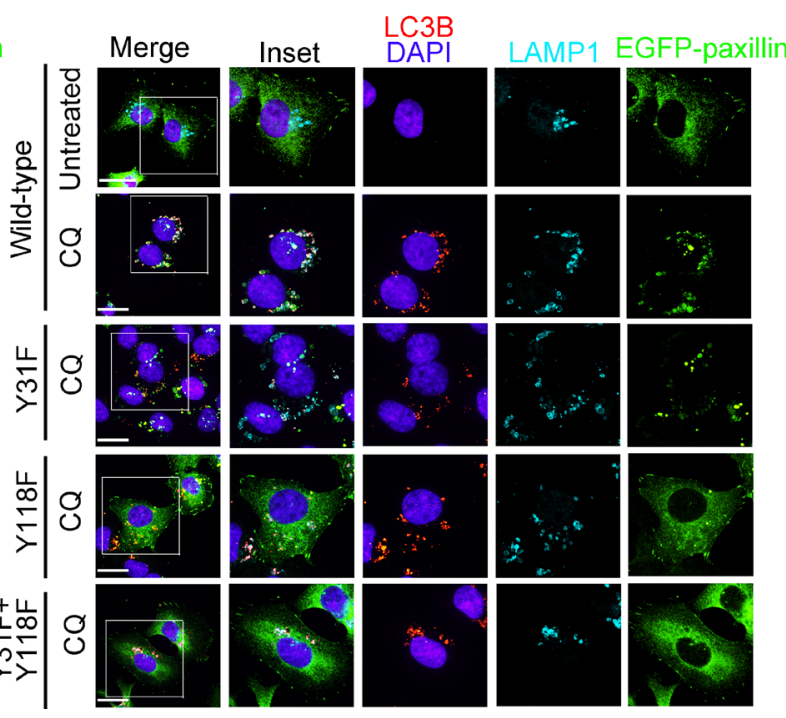

Figure 5: Tyrosine 118 phosphorylation of paxillin is essential for Rab7-mediated FA turnover via autophagy. (A) BT-20 cells expressing shNT or shRab7 were fixed and stained for anti-paxillin, anti-31Y-p-paxillin or 118Y-p-paxillin (red), antiRab7 antibody (green) and with DAPI (blue). Arrows indicate the cells with puncta. Scale bar, $20 \mu \mathrm{m}$. (B) Top: schematic illustration of the structure of paxillin and position of tyrosine 31 and 118. Bottom: lysates from BT-20 cells transfected with EGFP-paxillin WT, EGFP-paxillin-Y31F, EGFP-paxillin-Y118F or EGFP-paxillin-Y31F/Y118F were immunoblotted with antibodies against paxillin, 31Y-ppaxillin, 118Y-p-paxillin and anti- $\beta$-actin as an internal control. (C and D) Control and (shNT) Rab7-silenced BT-20 cells (shRab7) (C) or BT-20 control (untreated) and treated with chloroquine for $24 \mathrm{hr}$ (CQ) (D) were transfected with EGFP-paxillin WT, EGFP-paxillin-Y31F, EGFP-paxillin-Y118F or EGFP-paxillin-Y31F+Y118F plasmids (all green) respectively. Then, cells were immunostained with anti-LC3B antibody (red), anti-LAMP-1 antibody (cyan) and with DAPI (blue). Scale bar, $20 \mu \mathrm{m}$. Enlargements of the boxed regions are also shown indicating association of EGFP-paxillin, LC3B and LAMP-1. 
was dependent on the phosphorylation of paxillin at Y118 since expression of the paxillin mutant Y118F, which is unable to get phosphorylated (Figure 6B, left), failed to interact with LC3 (Figure 6B, right). Furthermore, we co-transfected BT-20 cells with GFP-paxillin and mCherry-LC3 which allowed us to follow their intracellular localization in live cell conditions. As shown in Figure 6C, 6D) and Supplementary Video 2, transient co-localization of EGFP-paxillin-WT and mCherry-LC3 are seen at FA sites. To further confirm that this transient interaction occurs during FA disassembly, we utilized the nocodazole-based assay as previously described [22]. As expected, immunocytochemistry results demonstrated transient colocalization between 118Y-p-paxillin and LC3 at plasma membrane protrusions $10 \mathrm{~min}$ post nocodazole washout (Supplementary Figure 4). Likewise, expression of Y118F-paxillin resulted in significantly lower incidence of this co-localization with LC3, along with its inability to specifically co-localize at FA site (Figure 6C, bottom). Equally important, siRNA knockdown of FAK and Src prior to co-immunoprecipitation studies had no impact on paxillin/LC3 interactions (Figure 6E and 6F), supporting that the autophagy-mediated regulation of paxillin turnover is independent of FAK or Src kinases, both of which are implicated in the phosphorylation of paxillin [21].

\section{c-Cbl is the main cargo receptor targeting Y118- p-paxillin to autophagosomes}

The E3 ubiquitin ligase activity of c-Cbl, via its LIR (light chain 3 (LC3)-interacting region) domain, has been reported to recruit Src to LC3 [23]. Additionally, c-Cbl has been reported to specifically interact with paxillin [24]. Therefore, in order to explore whether $\mathrm{c}-\mathrm{Cbl}$ mediates the LC3/paxillin interaction, we used immunofluorescence staining to investigate the association. We noticed the presence and co-localization of a c-Cbl/118Y-p-paxillin/LC3 complex at focal adhesions (Figure 7A). Next, we knocked down c-Cbl expression using siRNA (Figure 7B, left) and then pulled down the complex. As shown in Figure 7B (right panel), c-Cbl siRNA expression considerably reduced LC3 binding to paxillin. This interaction was independent of the E3 ubiquitin ligase activity of c-Cbl, as expression of a E3 ubiquitin ligase- defective mutant of c-Cbl (HA-CblC381A) still maintained an effective interaction with paxillin (Figure 7C). Interestingly, c-Cbl siRNA also caused the accumulation of $118 \mathrm{Y}-\mathrm{p}$-paxillin in BT-20 cells, an accumulation that can be reversed by the re-expression of either WT or C381A c-Cbl (Figure 7D). The significance of this accumulation was visualized by immunofluorescence, where enhanced 118Y-p-paxillin structures (density and number) were observed in BT-20 cells where c-Cbl was knocked down, as compared to control cells (Figure 7E). Furthermore, monitoring of EGFP-paxillin turnover in motile cells revealed lower disassembly rates in BT-20 cells where $\mathrm{c}-\mathrm{Cbl}$ is silenced, which was once again effectively rescued by re-expression of WT or C381A c-Cbl (Figure 7F).

\section{DISCUSSION}

Cell locomotion is controlled by actin cytoskeletonassociated adhesions, represented by a network of proteins among which the scaffolding protein paxillin plays a fundamental regulatory role in the formation of both nascent and mature focal adhesions at leading edges of motile cells [25-27]. These functions are attributed to multiple interactions of paxillin with FA partners, primarily involving its zinc-finger motifs and are tightly regulated by paxillin posttranslational modifications, including phosphorylations at tyrosine residues 31 and 118 [28-31]. The role of these phosphorylation sites in the regulation of FA dynamics is still debated since both phosphorylated and non-phosphorylated paxillin have been proposed to regulate lamellipodial protrusions [32,33], as well as formation [34, 35] and turnover of adhesion formation [21].

Our study identified the striking impact of Rab7 (implicated in transport from early to late endosomes of late endocytic structures/lysosomes) in the regulation of paxillin tyrosine-118 phosphorylation turnover via the autophagy pathway, an evolutionary conserved catabolic process which delivers cytoplasmic cargo to lysosomes via double membrane vesicles called autophagosomes [36] but not through proteasomal degradation [37]. Knockdown of Rab7 but not Rab5 (a regulator of early endosome biogenesis) or Rab11 (involved in perinuclear recycling of endocytosed proteins) (data not shown) prevented 118Y-p-paxillin recruitment and accumulation in the autophagosomes (Figure 4B). As well, we confirmed that the Rab7 mutant lacking GTPase activity failed to rescue118Y-p-Pax recruitment to autophagosomes, highlighting the importance of Rab 7 GTPase activity (Figure 2D), which requires a switch between the GDPbound off-state and a GTP-bound on-state, necessary for paxillin recognition and recuitment to autophagosomes.

The critical function of Rab7 to recruit autophagy effector FA proteins is of fundamental importance given that autophagy, an evolutionary conserved catabolic process which delivers cytoplasmic cargo to lysosomes via autophagosomes [36], is implicated in the regulation of cell migration $[38,39]$. In our study, downregulation of autophagy using both genetic and pharmacological approaches resulted in selective accumulation of 118Y-ppaxillin but not Y31-p-paxillin in autophagosomes (Figure 5A). These results were corroborated by imaging studies confirming intracellular colocalization of 118Y-ppaxillin but not $\mathrm{Y} 31$ with $\mathrm{LC} 3$ at cell protrusions during FA disassembly (Figure 5C, 5D). In contrast to a previous study showing that mutation of both $\mathrm{Y} 31$ and Y118 to non-phosphorylatable amino acids impairs the disassembly of adhesions at FA sites of the leading edge 


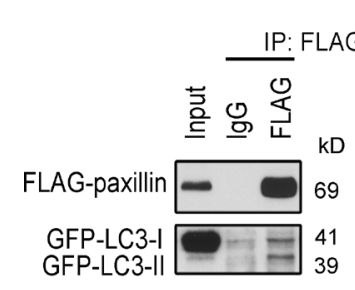

C

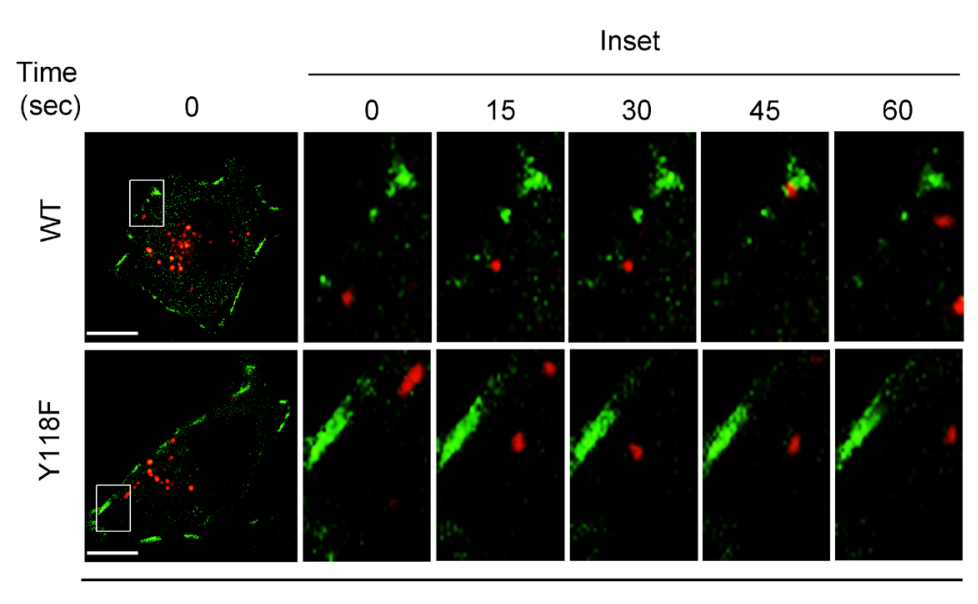

EGFP-paxillin/ mCherry-LC3

$\mathrm{E}$

F
$\mathrm{D}$

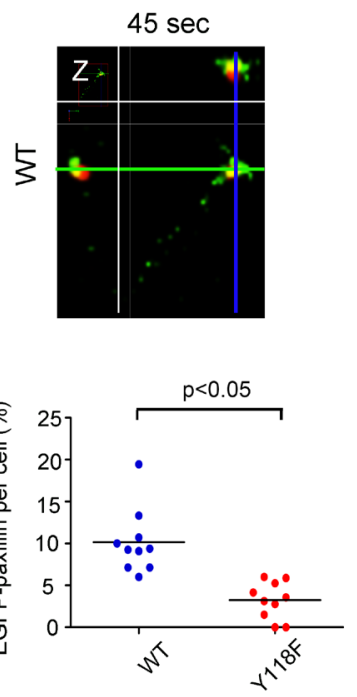

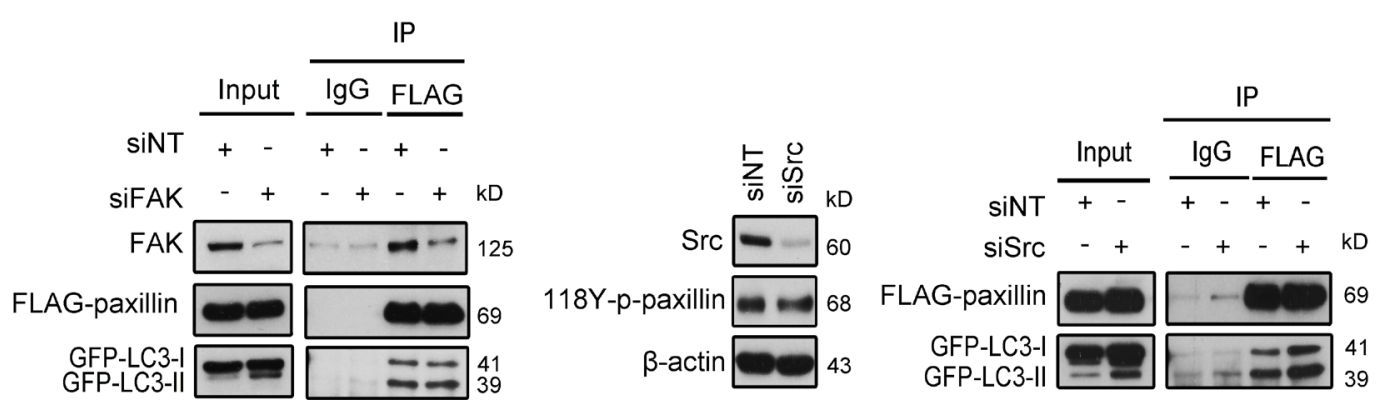

Figure 6: Tyrosine 118 phosphorylation of paxillin modulates its association with the autophagic marker LC3 at cell plasma membrane protrusions. (A) BT-20 cells were transfected with FLAG-paxillin and GFP-LC3 plasmids for $24 \mathrm{~h}$ and immunoprecipitated with either anti-IgG or anti-FLAG antibodies. Lysates were then immunoblotted with anti-FLAG and anti-GFP antibodies. (B) Left: FLAG protein was immunoprecipitated from BT-20 cells transfected with either wild-type FLAG-paxillin (FLAGpaxillin-WT) or FLAG-paxillin with point mutation at amino acid 118 (FLAG-paxillin-Y118F) for 24 hours and immunoblotted with anti-118Y-p-paxillin antibody. Right: BT-20 cells were transfected with either FLAG-paxillin-WT or FLAG-paxillin-Y118F and GFP-LC3 plasmids for $24 \mathrm{~h}$ and immunoprecipitated with either anti-IgG or anti-GFP antibodies. Lysates were then immunoblotted with anti-FLAG and anti-GFP antibodies. (C) BT-20 cells were transfected with either EGFP-paxillin wild-type (WT) or EGFP-paxillin-Y118F (Y118F) plasmids (green) and mCherry-LC3 plasmids (red) for $24 \mathrm{~h}$, then plated on chamber slide. Next, cells were monitored for the trafficking of EGFP-paxillin and mCherry-LC3 by time-lapse spinning disc microscopy. Scale bar, $5 \mu \mathrm{m}$. Higher-magnification images of the inserts are also shown indicating path of EGFP-paxillin and mCherry-LC3 at cell protrusions. (D) Top, Enlargements and cross-sections of the confocal-z-planes of the boxed regions are also shown indicating association of EGFP-paxillin-WT and mCherry-LC3 at 45 sec. Bottom: quantification of the percentage of dynamic EGFP-paxillin labeling FAs per cell targeted by mCherry-LC3. Scatter plot shows individual single cells and mean line. $n=125$ mCherry-LC3 vesicles targeted to FA in EGFP-paxillin WT and 169 mCherry-LC3 vesicles targeted to FAs in EGFP-paxillin-Y118F group from 10 single cells. (E) siRNA silenced FAK BT-20 cells were transfected with FLAG-paxillin and GFP-LC3 plasmids for $24 \mathrm{~h}$ and immunoprecipitated by either anti-IgG or anti-FLAG antibodies. Lysates were then immunoblotted with anti-FAK, anti-FLAG and anti-GFP antibodies. (F) Left: BT-20 cells were transiently transfected with non-targeted or Src siRNA proteins were extracted, and then immunoblotted with anti-Src, anti-118Y-p-paxillin and anti- $\beta$-actin antibodies. Right: FLAG-paxillin was immunoprecipitated from siNT and siSrc cells expressing FLAG-paxillin and GFP-LC3, then immunoblotted with anti-FLAG and anti-GFP antibodies. 
A
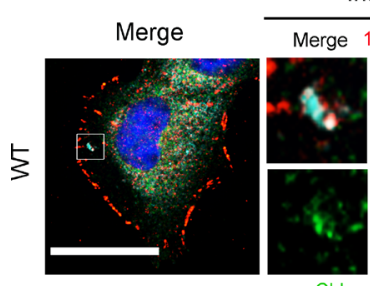

$\mathrm{c}-\mathrm{Cb}$

C

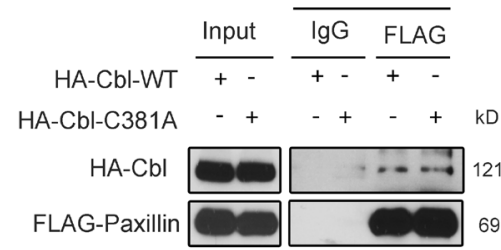

E
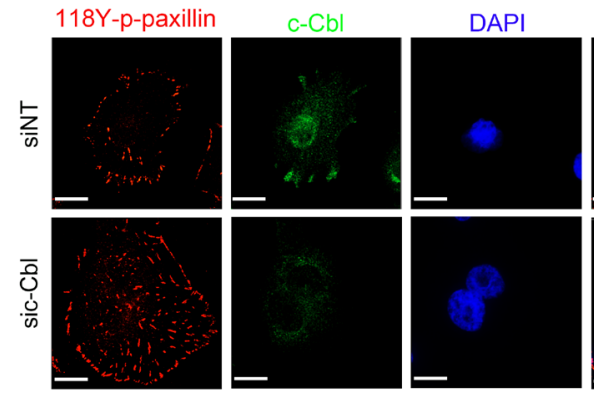

F

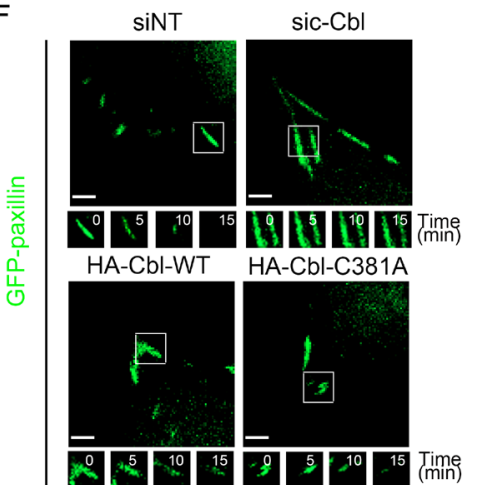

B

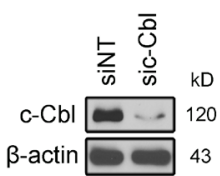

D
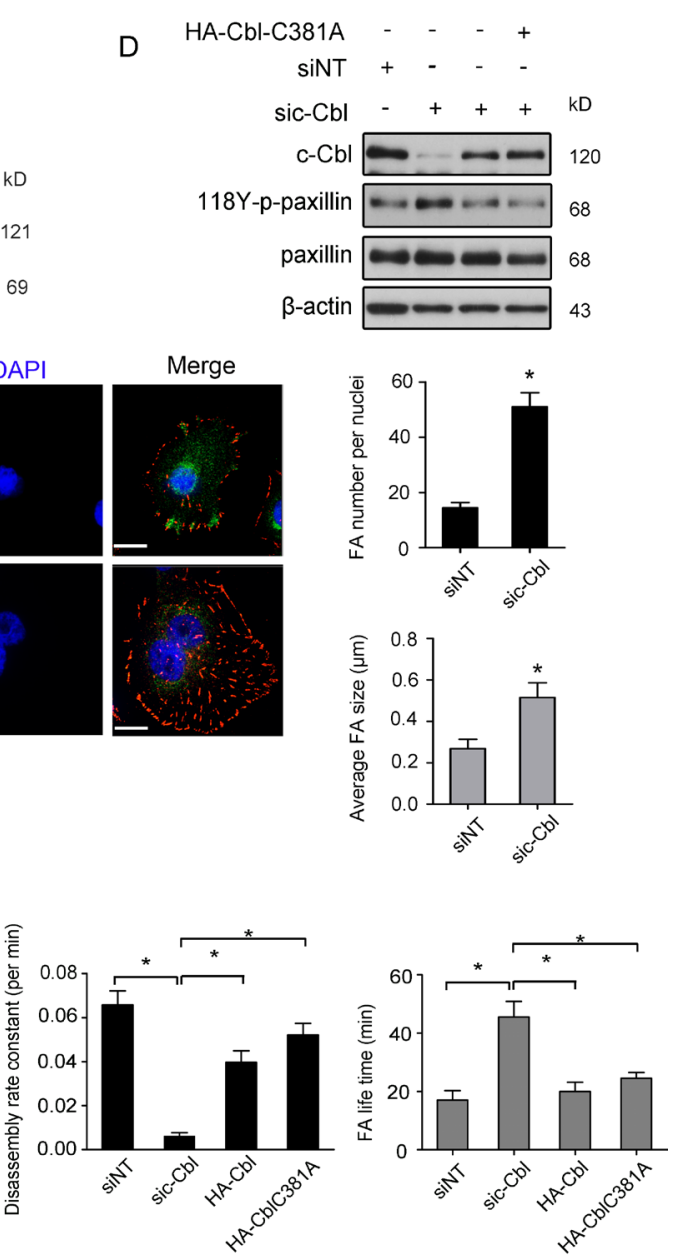

Figure 7: c-Cbl is the major cargo receptor mediating LC3 interaction with paxillin. (A) BT-20 cells were fixed and stained for anti-118Y-p-paxillin antibody (red), anti-LC3B antibody (cyan), anti-c-Cbl antibody (green) and with DAPI (blue). Scale bar, $20 \mu \mathrm{m}$. Enlargements of the boxed regions are also shown indicating association of 118Y-p-paxillin, LC3B and c-Cbl. (B) Left: BT-20 cells were transfected with either NT or c-Cbl siRNA for $48 \mathrm{~h}$, then immunoblotted with anti-c-Cbl anti- $\beta$-actin antibodies. Right: BT-20 cells were transfected with non-targeted or c-Cbl siRNA for $24 \mathrm{~h}$ and then transfected with FLAG-paxillin and GFP-LC3 plasmids for another $24 \mathrm{~h}$ and immunoprecipitated by either anti-IgG or anti-FLAG antibodies. Lysates were then immunoblotted with anti-FLAG and anti-GFP antibodies. (C) BT-20 cells were transfected with either HA-Cbl wild-type plasmids (HA-Cbl-WT) or HA-Cbl with point mutation on a.a 381. (HA-Cbl-C381A) for $24 \mathrm{~h}$ and immunoprecipitated by either anti-IgG or anti-FLAG antibodies. Lysates were then immunoblotted with anti-FLAG and anti-HA antibodies. (D) BT-20 cells were transfected with non-targeted or c-Cbl siRNA for $24 \mathrm{~h}$ and then were either rescued by HA-Cbl-WT or HA-Cbl-C381A plasmids. After $24 \mathrm{~h}$, cells were lysed and immunoblotted with antibodies against c-Cbl, 118Y-p-paxillin, paxillin and anti- $\beta$-actin as an internal control. (E) Left, BT-20 cells transfected with non-targeted or c-Cbl siRNA for $48 \mathrm{~h}$ were stained with anti-118Y-p-paxillin antibody (red), c-Cbl antibody (green) and DAPI (blue). Scale bar, $20 \mu \mathrm{m}$. Right, quantification of FA number per cells and average FA size. Data are presented as mean \pm SEM $\left({ }^{*} p<0.05, n=10\right.$ cells) (F) Left: Serum-starved siNT or sicCbl BT-20 cells rescued with either HA-Cbl wild-type plasmids (HA-Cbl-WT) or HA-Cbl with point mutation on a.a 381 (HA-Cbl-C381A) were transfected with GFP-paxillin for $24 \mathrm{~h}$, then plated on chamber slide, stimulated by $20 \mathrm{ng} / \mathrm{ml}$ EGF and analyzed for FA turnover by time-lapse spinning disc microscopy. Scale bar, $2 \mu \mathrm{m}$. Higher-magnification images of the inserts are also shown indicating positions of paxillin-containing FAs. Right: FAs disassembly rate and FA life time in siNT, sic-Cbl. sic-Cbl+ HA-Cbl-WT and sic-Cbl+ HA-Cbl-C381A cells were quantified (mean $\pm \mathrm{SEM}, n=44 \mathrm{FAs}$ in siNT, $38 \mathrm{FAs}$ in sic-Cbl, 45 FAs in HA-Cbl rescued and 52 FAs in HA-Cbl-C381A groups from 10 single cells, $\left.{ }^{*} p<0.05\right)$. 
of migrating cells [21, 40], our study revealed a distinct function of Y118, which unlike Y31, can selectively target paxillin to autophagosomes for degradation, triggering FA disassembly.

Paxillin has a proline-rich motif that binds to the Src SH3 domain and Src-FAK kinases, which mediate tyrosine phosphorylation of paxillin [41]. In turn, paxillin interacts with the FAT domain of FAK believed to direct FAK to FA sites. Furthermore, it has been shown that it is the phosphorylated form of paxillin that predominantly recruits FAK into the adhesion sites and that paxillin-induced adhesion turnover occurs in an FAK-dependent manner [40]. To rule out the possibility that paxillin recruitment to autophagosomes is a result of a complex involving Src or FAK, we demonstrated that Src or FAK knockdown had no impact on Y118-p-paxillin recruitment to autophagosomes or interaction with LC3B (Figure 6E, 6F), suggesting that recruitment to autophagosomes occurs in a Src- and FAKindependent manner. In fact, as shown in Supplementary Figure 5, neither FAK, 397Y-p-FAK nor 861Y-p-FAK accumulated in puncta in Rab7-deficient cells, compared to matched control cells.

During selective autophagy, recognition of protein targets involves direct interaction between the substrate and LC3 through LIR motifs, which include cargo receptor proteins such as c-Cbl, NBR1 and p62 [42]. Interestingly, while writing this manuscript a recent study reported that autophagy regulates FA turnover via the cargo protein NBR1 [43]. In our study, using siRNA targeting NBR1 prior to pull down revealed that although NBR1 regulates EGFP-LC3/FLAG-paxillin interaction and colocalizes with $118 \mathrm{Y}$-p-paxillin at FA site, the efficiency of Y118-phospho-paxillin localization to autophagosomes is weaker compared to when manipulating c-Cbl (Supplementary Figure 6). Therefore, we conclude that $\mathrm{c}-\mathrm{Cbl}$ is a major cargo receptor but not the ubiquitinbinding scaffolding protein $\mathrm{p} 62$, which also interacts with LC3 during autophagy. c-Cbl has ubiquitin ligase activity and one study reported that inhibition of c-Cbl ubiquitin ligase activity prevented paxillin interaction and degradation in myocytes [44]. However, in our study we demonstrate that c-Cbl ligase activity had no impact on paxillin/c-Cbl interaction neither on 118Y-ppaxillin expression and turnover (Figure 7D, 7F). In support of our findings, autophagic targeting of active $\mathrm{Src}$ is reported to be mediated by $\mathrm{c}-\mathrm{Cbl}$ independently of c-Cbl E3 ligase activity [23]. Nevertheless, we cannot rule out a contribution of additional posttranslational modifications of paxillin such as serine phosphorylation $[37,45]$ and ubiquitination [46], both deserving further investigations. Moreover, in agreement with previously published studies, paxillin phosphorylation at Y118 may result in a conformational change in paxillin creating a $\mathrm{Crk}$ binding site [30], which in turn possesses a cbl binding domain [47], thereby aiding in paxillin recruitment and detachment from FA complexes. Consistent with recent observations described by Sharifi et al. [15], this is in sharp contrast to what we observed in mouse derived cell lines, where phosphorylation at Y118-p-paxillin was not required for autophagosomal regulation of paxillin and/ or its interaction with LC3 in the mouse mammary tumor derived cell line 4T1, or in FAK -/- or SYF -/- mouse embryonic fibroblasts (data not shown), further supporting a tissue-type specific mechanism for this turnover.

In summary, our data provides new mechanistic insights into the role of Rab7 in targeting Y118 sitespecific phosphorylation of paxillin to the autophagy pathway to promote focal adhesion turnover (summarized in Supplementary Figure 7) in human breast cancer cells, a process essential for cell locomotion. Noticeable, many of the protein networks involved in these pathways have been reported to be upregulated in many human cancers and can predict invasiveness, these include Rab7 [12] in agreement with another study in melanoma [13], paxillin [48] and Atg proteins $[49,50]$. Therefore, molecular mechanisms described herein further enlighten the molecular basis involved in these associations.

\section{MATERIALS AND METHODS}

\section{Materials}

Antibodies used were as follows: anti-118Y-ppaxillin, anti-31Y-p-paxillin and anti-397Y-p-FAK (Invitrogen); anti-GFP, anti- $\beta$-actin, anti-Rab7, anti-p62 and anti-LC3B (Santa Cruz); anti-416Y-p-Src and antiNBR1 (Cell signaling), anti-GFP (Roche); anti-LAMP-1 and anti-HA (Abcam); anti-LC3B, anti-Atg12 and antic-Cbl (Novus); anti-Rab5a (BD transduction laboratory); anti-paxillin, anti-Src and anti-FAK (Millipore); antiLAMP1 (R\&D systems); anti-FLAG (Sigma). Anti-mouse and anti-rabbit IgG-peroxidase-conjugated secondary antibodies for Western blot assays were from Bio-Rad. Alexa Fluor594 and 488 conjugated secondary antibodies were from Life Technology. Alexa Fluor 647 conjugated secondary antibodies were from Millipore. Epidermal growth factor was from Gibco; Histodenz (Nycodenz), nocodazole and chloroquine (CQ) were from SigmaAldrich. When indicated CQ was used at a concentration of $20 \mu \mathrm{M}$, a non-toxic concentration found to induce optimal autophagy inhibition (based on changes in LC3I/ II ratio), which is in accordance with previous studies (Sandilands et. al.).

\section{Cell lines and cell culture}

The breast cancer cell lines MDA-231, MCF-7, BT-20 and 4T1 were obtained from the American Type Culture Collection. MDA231-M2 is a highly metastatic variant of MDA-MB-231 cells we isolated from lung nodules induced by the parental MDA-MB-231 [51]. All cell lines were maintained in RPMI 1640 (Fisher) 
supplemented with $10 \%$ FBS and with $1 \%$ penicillin and streptomycin antibiotics.

\section{Plasmids construction}

EGFP-paxillin (plasmid \#15233), FLAG-paxillin (plasmid \#15212), GFP-LC3 (plasmid \#22405), mCherryLC3 (plasmid \#40827), GFP-Rab7 (plasmid \#12605), GFP-Rab7-T22N (plasmid \#12662) were obtained from Addgene. FLAG-paxillin-Y118F was further modified by GeneScript Inc. Primers used for mutation of the EGFP-paxillin and HA-Cbl (kindly provided by Dr. Youcef Yarden, Department of Biological Regulation, The Weizmann Institute of Science, Rehovot, Israel) using site-directed mutagenesis kit (Stratagene): EGFPpaxillin-Y31F: sense, 5'-CAGAGGAAACGCCTTT CTCCTACCAACTGG-3'; antisense, 5'-CCAGTT GGGTA GGAGAAAGGCGTTTCCTCTG-3', EGFP-paxillinY118F: sense, 5'- GAGGAGGAA CACCTGTTCAGCTT CCCAAACAG-3'; antisense, 5'-CTTGTTTGGGAAGCT GAACACGTGTTCCTCCTC-3' and HA-Cbl-C381A: sense, 5'-GATGGGCTCCACATTCCAACTAGCTAAAA TATGTGCTGAAAATGATA -3'; antisense, 5'-TATCA TTTTCAGCACATATTTTAGCTAGT TGGAATGTGG AGCCCATC-3'. All plasmids were transfected into BT20 cells using Lipofectamine LTX and PLUS reagents (Invitrogen) according to the manufacturer's instructions.

\section{siRNA gene knockdown}

Non-targeted siRNA sequence: sense, 5'-UUCUCC GAACGUGUCA CGUdTdT-3'; antisense, 5'-ACGGUG ACACGUUCGGAGAAdTdT-3', c-Cbl siRNA sequences: sense, 5'-GGGAAGGCUUCUAUUUGUUdTdT-3'; antisense, 5'-AACAAAUAG AAGCCUUCCCdTdT-3', p62 siRNA sequence: sense, 5'-GCAUUGAAGUUGAUAUCGAUd TdT-3'; antisense, 5'-AUCGAUAUCAACUUCAAUGC dTdT-3', NBR1 siRNA sequence: sense, 5'-GGAGUGG AUUUACCAGUUAUUdTdT-3'; antisense, 5'-AAUAA CUGGUAAAUCCACUCCdand FAK siRNA sequence: sense, 5'-GCGAUUAUAUGUUAGAGAUAG dTdT-3'; antisense, 5'-CUAUCUCUAACAUAUAAUCGCdTdT-3' were from Dharmacon. Src siRNA was from Sigma with the following sequences: sense, 5'-CUGAGAGGG CGGUGGGUA UdTdT-3' (WD04736566); anti-sense, 5'-AUACCCACCGCCCUCUCAGdTdT-3' (WD04736567). siRNA for Rab5a: sequence 1 (siGENOME siRNA D-004009-01); and sequence 2 (siGENOME siRNA D-004009-02); Atg12: sequence 1 (siGENOME siRNA D010212-03); and sequence 2 (siGENOME siRNA D010212-05) were from Thermo Fisher Scientific. Control siRNA (Cell Signalling) or target siRNA oligonucleotides were expressed in cells by incubated with INTERFERin (Polyplus transfection) in serum-free RPMI medium according to the manufacturer's instruction.

\section{Generation of stable Rab7-knockdown cells}

Stable Rab7 knockdown cells were generated from a polyclonal population as described previously (Benlimame et al., 2005). The target shRNA sequence for Rab7 (GenBank/EMBL/DDBJ, accession no. NM_004637.5) was 5'-CTGCTGCGTTCTGGTATTTGA-3' (targeting nucleotide 478-498). This sequence was cloned as an inverted repeat into pSUPER.puro vector according to the manufacturer's instructions (OligoEngine).

\section{Immunoblotting assay}

Sub-confluent cells were washed with PBS, lysed in RIPA buffer (50 mM Tris- $\mathrm{HCl}$ at $\mathrm{pH} 7.5,150 \mathrm{mM}$ sodium chloride, $1 \%$ tritonX-100, $0.1 \%$ SDS, $2 \mathrm{mM}$ EDTA and $25 \mathrm{mM}$ sodium fluoride) supplemented with $1 \mathrm{mM}$ PMSF and protease inhibitor cocktail (Roche) for $10 \mathrm{~min}$ on ice and centrifuged $\left(13,000 \mathrm{rpm}\right.$ at $4^{\circ} \mathrm{C}$ for $20 \mathrm{~min})$ to separate cell lysate. Cell lysate $(50 \mu \mathrm{g}$ protein, as measured by the Bradford protein assay) was then added with SDS sample buffer (Tris at $\mathrm{pH} 6.8,20 \%$ glycerol, $5 \%$ SDS, bromophenol blue and $\beta$-mercaptoethanol) and boiled for $5 \mathrm{~min}$. Samples were then resolved through 13\% SDS-PAGE gels, transferred to nitrocellulose membrane, blotted with primary antibodies at different dilution in cold room overnight, and then amplified with horseradish peroxidase-conjugated secondary antibodies for $1 \mathrm{~h}$ in room temperature and enhanced by chemiluminescence detection system.

\section{Immunoprecipitation assays}

Cells transfected with both FLAG-paxillin (or FLAG-paxillin-Y118F) and GFP-LC3 were washed with PBS and lysed in lysis buffer $(50 \mathrm{mM}$ Tris- $\mathrm{HCl}$ at $\mathrm{pH}$ 8.0, $50 \mathrm{mM}$ sodium chloride, $0.5 \%$ tritonX-100, $0.5 \%$ 2 NP-40, $0.5 \%$ deoxycholate, $0.1 \%$ SDS and $5 \mathrm{mM}$ EDTA) supplemented with $1 \mathrm{mM}$ PMSF and protease inhibitor cocktail (Roche) for $10 \mathrm{~min}$ on ice and cell lysate isolated following centrifugation $(13,000 \mathrm{rpm}$ at $4^{\circ} \mathrm{C}$ for $\left.20 \mathrm{~min}\right)$. Cell lysate $(1000 \mu \mathrm{g}$ protein, measured by bradford protein assay) was immunoprecipitated with either $2 \mu \mathrm{g}$ anti-FLAG or anti-GFP antibodies or IgG (sigma) overnight at $4^{\circ} \mathrm{C}$, and then incubated with protein $\mathrm{G}$ magnetic beads (Millipore) for $1 \mathrm{~h}$ at $4^{\circ} \mathrm{C}$. Beads were washed three times with IP buffer $(50 \mathrm{mM}$ Tris- $\mathrm{HCl}$ at $\mathrm{pH} 8.0,50 \mathrm{mM}$ sodium chloride, $1 \%$ tritonX-100 and 5 mM EDTA), then added with SDS sample buffer (Tris at $\mathrm{pH} 6.8,20 \%$ glycerol, 5\% SDS, bromophenol blue and $\beta$-mercaptoethanol) and boiled for $5 \mathrm{~min}$, then separated by $10 \%$ SDS-PAGE. For interaction between $\mathrm{c}-\mathrm{Cbl}$ and paxillin, cells were transfected with HA-Cbl (or HA-CblC381A) and FLAG-paxillin and pulled down using antiFLAG antibody. 


\section{Density gradient centrifugation for autophagosome enrichment and characterization}

Cells $\left(1 \times 10^{8}\right)$ were washed with PBS and resuspended in $1 \mathrm{ml}$ cold buffer A $(250 \mathrm{mM}, 10 \mathrm{mM}$ HEPES, pH 7.4, $1 \mathrm{mM}$ EDTA) supplemented with $1 \mathrm{mM}$ PMSF and protease inhibitor cocktail (Roche). Cells were disrupted by repeated aspiration through 26 gauge needle and centrifuged $\left(2,000 \mathrm{rpm}\right.$ at $4{ }^{\circ} \mathrm{C}$ for $10 \mathrm{~min}$ ) and $0.95 \mathrm{ml}$ supernatant was diluted with $1.45 \mathrm{ml}$ $85.6 \%$ Nycodenz (Sigma) solution to become $52 \%$, then placed on the bottom of the $13 \mathrm{ml}$ ultra-clear centrifuge tube (Beckman). A discontinuous Nycodenz gradient $(26 \%, 24 \%, 20 \%, 15 \%)$ was layered on the top of the $52 \%$ supernatant and centrifuged at $24,700 \mathrm{rpm}$ at $4^{\circ} \mathrm{C}$ for $3 \mathrm{~h}$ in a SW41 rotor (Beckman). Fractions were washed with cold PBS and collected as indicated (A1, A2, L, M). Pellets were collected at $14,800 \mathrm{rpm}, 4^{\circ} \mathrm{C}$ for $1 \mathrm{~h}$ and used for immunoblotting experiments.

\section{Immunofluorescence microscopy}

Cells were grown on 18-mm cover glass coated with $5 \mu \mathrm{g} / \mathrm{ml}$ fibronectin for $24 \mathrm{~h}$ in $4^{\circ} \mathrm{C}$, placed in 6-well culture plate for $24 \mathrm{~h}$, rinsed in PBS, fixed with $4 \%$ paraformaldehyde/PBS for $10 \mathrm{~min}$, washed twice in PBS with $0.2 \%$ TritonX-100, blocked in PBS with $0.2 \%$ Triton $\mathrm{X}-100$ containing $1 \%$ BSA (Bioshop) and incubated with primary antibodies overnight in $4^{\circ} \mathrm{C}$ (all in $1 / 100$ diluted by blocking solution). The cells were washed with PBS containing $0.2 \%$ TritonX-100 and subsequently incubated with Alexa Fluor 488-labelled, Alexa Fluor 594-labelled, or Alexa Fluor 647-labelled secondary antibodies (all were used at 1/500 dilution in blocking solution) for $1 \mathrm{hr}$ in room temperature. The nuclei were stained with DAPI $(0.1 \mu \mathrm{g} / \mathrm{ml})$ for $5 \mathrm{~min}$ before mounted with aqueous mounting medium. Cells were imaged using WaveFX spinning disk confocal microscope system (Quorum Technologies INC.). Images shown are representative of three independent experiments

\section{Live cell imaging microscopy}

For the monitoring of FA turnover, cells were transfected with EGFP-paxillin and plated in RPMI 1640 serum-free medium on a multiwell chambered coverglass (LabTek) prepared by coating overnight in $4^{\circ} \mathrm{C}$ with $5 \mu \mathrm{g} / \mathrm{ml}$ fibronectin. The coverglass was directly placed on a heated stage with $5 \% \mathrm{CO}_{2}$ and stimulated with $20 \mathrm{ng} / \mathrm{ml}$ epidermal growth factor. Fluorescent images were captured every $5 \mathrm{~min}$ for $2 \mathrm{~h}$ using a heated $64 \mathrm{X}$ NA 1.40 objective at WaveFX spinning disk confocal microscope system (Quorum Technologies INC.). Fluorescence intensities of individual adhesions were measured over time by Volocity imaging software
(PerkinElmer) and quantified according to the previously described protocol (Franco et. al 2004b; Webb et al., 2004). Measurements were made on at least 20 individual adhesions in four separated cells for both Rab7 silenced and control groups. For investigating colozalization, cells were transfected with both GFP-paxillin and mcherryLC3, then plated in RPMI 1640 medium with $10 \%$ FBS on a multiwell chambered coverglass (LabTek). Fluorescent images were captured every $15 \mathrm{sec}$ for $2 \mathrm{~h}$ using a heated 63 X NA 1.40 objective using a WaveFX spinning disk confocal microscope system.

\section{Nocodazole-based FA disassembly assay}

FA disassembly and reformation, cells were grown on glass-coverslips coated with $5 \mu \mathrm{g} / \mathrm{ml}$ fibronectin for $24 \mathrm{~h}$ in $4^{\circ} \mathrm{C}$, serum starved for $4 \mathrm{~h}$ in RPMI1640 serum free medium and then treated with $2 \mu \mathrm{M}$ nocodazole in serumfree medium for $2 \mathrm{~h}$ to allow a complete depolymerization of microtubules. Nocodazole was washed-out with serum-free medium and cells were further incubated at $37^{\circ} \mathrm{C}$ to allow a reformation of FA structure. Subsequently, cells were fixed and processed for immunofluorescence staining at different time intervals. Cells were stained with Rab7, 118Y-ppaxillin and LC3B. Focal adhesion dynamics was analyzed as previously described [22] using Image J software.

\section{Live cell locomotion assay}

Cells were seeded at very low density in serum-free medium on a multiwell chambered coverglass (LabTek) prepared by coating overnight in $4^{\circ} \mathrm{C}$ with $5 \mu \mathrm{g} / \mathrm{ml}$ fibronectin. The coverglass was placed on a heated stage with $5 \% \mathrm{CO}_{2}$ and stimulated with $20 \mathrm{ng} / \mathrm{ml}$ epidermal growth factor before monitoring the cell movement using a heated 40 X NA 1.40 objective at WaveFX spinning disk confocal microscope system (Quorum Technologies INC.). Single cell speed was determined by manually tracing the cell periphery every $20 \mathrm{~min}$ for $2 \mathrm{~h}$ by using Volocity imaging software (PerkinElmer).

\section{In vitro statistical analysis}

All experiments counting 118Y-p-paxillin and LC3 puncta were performed in triplicate with similar results. Quantitative data in single cell migration experiments and puncta quantification were performed in 15 separate cells for both Rab7 silenced and control cells. For FA disassembly and FA life time quantification, measurements were made on at least 40 focal adhesions in 10 separate Rab7 silenced and control cells. All data are presented as mean \pm SEM using Prism (GraphPad Software). Statistical significance was analyzed using unpaired two-tailed Student's $t$ test. Data were deemed to be statistically significant if $P<0.05$. Error bars indicate SEM unless otherwise indicated. 


\section{In vivo xenograft model of breast cancer metastasis}

All experiments were carried out according to protocol number 4101 of the McGill University Animal Care Committee. MDA231-M2 cells $\left(1 \times 10^{6}\right.$ cells/ each mouse) expressing scramble shRNA and their matched cells stably expressing Rab7 shRNA were transplanted into the mammary fat pad of SCID mice. Tumor size was measured using a caliper, and tumor volume was calculated as $\pi / 6$ (length $\times$ width $^{2}$ ). Primary tumors were excised once they had reached a mean size of $0.8 \mathrm{~cm}^{3}$. The wound was closed with a single layer of surgical clips. Mice were sacrificed 40 days after transplanting. The lungs were fixed in $10 \%$ Bouin's fixative and lung metastatic nodules on the surface were counted using a stereomicroscope (Optimax; Leica). Statistical comparison between groups was performed using a computer-based statistical package from Statistical Product and Service Solution (Chicago, IL) as we described earlier [52].

\section{Authors'contributions}

Chia-Hao Chang conducted all of the experiments presented in the manuscript and wrote the manuscript. Dr. Krikor Bijian designed and guided all the experiments. Dinghong Qiu constructed the stable cell line expressing Rab7 shRNA and plasmids. Jie Su carried out the in vivo experiments reported. Amine Saad helped troubleshoot experimental conditions of co-immunoprecipitation assays. Michael S. Dahabieh is a student from Dr. Wilson H Miller'Jr's lab who guided the density gradient centrifugation studies for autophagosome enrichment. Manuscript was then revised by Dr. Moulay Alaoui-Jamali and Dr. Krikor Bijian.

\section{ACKNOWLEDGMENTS}

This work was supported by the Quebec Breast Cancer Foundation.

\section{CONFLICTS OF INTEREST}

None.

\section{FUNDING}

This work was supported by the Quebec Breast Cancer Foundation.

\section{REFERENCES}

1. Friedl P, Wolf K. Plasticity of cell migration: a multiscale tuning model. J Cell Biol. 2010; 188:11-9. doi: 10.1083/ jcb.200909003.
2. Ridley AJ, Schwartz MA, Burridge K, Firtel RA, Ginsberg MH, Borisy G, Parsons JT, Horwitz AR. Cell migration: integrating signals from front to back. Science. 2003; 302:1704-9. doi: 10.1126/science.1092053.

3. Fox JW, Lamperti ED, Eksioglu YZ, Hong SE, Feng Y, Graham DA, Scheffer IE, Dobyns WB, Hirsch BA, Radtke RA, Berkovic SF, Huttenlocher PR, Walsh CA. Mutations in filamin 1 prevent migration of cerebral cortical neurons in human periventricular heterotopia. Neuron. 1998; 21:1315-25.

4. Di Donato N, Rump A, Koenig R, Der Kaloustian VM, Halal F, Sonntag K, Krause C, Hackmann K, Hahn G, Schrock E, Verloes A. Severe forms of Baraitser-Winter syndrome are caused by ACTB mutations rather than ACTG1 mutations. Eur J Hum Genet. 2014; 22:179-83. doi: 10.1038/ejhg.2013.130.

5. Friedl P, Wolf K. Tumour-cell invasion and migration: diversity and escape mechanisms. Nat Rev Cancer. 2003; 3:362-74. doi: 10.1038/nrc1075.

6. Gardel ML, Schneider IC, Aratyn-Schaus Y, Waterman CM. Mechanical integration of actin and adhesion dynamics in cell migration. Annu Rev Cell Dev Biol. 2010; 26:315-33. doi: 10.1146/annurev.cellbio.011209.122036.

7. Pellinen T, Arjonen A, Vuoriluoto K, Kallio K, Fransen JA, Ivaska J. Small GTPase Rab21 regulates cell adhesion and controls endosomal traffic of beta1-integrins. J Cell Biol. 2006; 173:767-80. doi: 10.1083/jcb.200509019.

8. Liu SS, Chen XM, Zheng HX, Shi SL, Li Y. Knockdown of Rab5a expression decreases cancer cell motility and invasion through integrin-mediated signaling pathway. J Biomed Sci. 2011; 18:58. doi: 10.1186/1423-0127-18-58.

9. Mendoza P, Ortiz R, Diaz J, Quest AF, Leyton L, Stupack D, Torres VA. Rab5 activation promotes focal adhesion disassembly, migration and invasiveness in tumor cells. J Cell Sci. 2013; 126:3835-47. doi: 10.1242/jcs.119727.

10. Palamidessi A, Frittoli E, Ducano N, Offenhauser N, Sigismund S, Kajiho H, Parazzoli D, Oldani A, Gobbi M, Serini G, Di Fiore PP, Scita G, Lanzetti L. The GTPaseactivating protein $\mathrm{RN}$-tre controls focal adhesion turnover and cell migration. Curr Biol. 2013; 23:2355-64. doi: 10.1016/j.cub.2013.09.060.

11. Alanko J, Mai A, Jacquemet G, Schauer K, Kaukonen R, Saari M, Goud B, Ivaska J. Integrin endosomal signalling suppresses anoikis. Nat Cell Biol. 2015; 17:1412-21. doi: $10.1038 /$ ncb3250.

12. da Silva SD, Marchi FA, Xu B, Bijian K, Alobaid F, Mlynarek A, Rogatto SR, Hier M, Kowalski LP, AlaouiJamali MA. Predominant Rab-GTPase amplicons contributing to oral squamous cell carcinoma progression to metastasis. Oncotarget. 2015; 6:21950-63. doi: 10.18632/ oncotarget. 4277 .

13. Alonso-Curbelo D, Riveiro-Falkenbach E, PerezGuijarro E, Cifdaloz M, Karras P, Osterloh L, Megias D, Canon E, Calvo TG, Olmeda D, Gomez-Lopez G, Grana O, 
Sanchez-Arevalo Lobo VJ, et al. RAB7 controls melanoma progression by exploiting a lineage-specific wiring of the endolysosomal pathway. Cancer Cell. 2014; 26:61-76. doi: 10.1016/j.ccr.2014.04.030.

14. Davidson B, Zhang Z, Kleinberg L, Li M, Florenes VA, Wang TL, Shih Ie M. Gene expression signatures differentiate ovarian/peritoneal serous carcinoma from diffuse malignant peritoneal mesothelioma. Clin Cancer Res. 2006; 12:5944-50. doi: 10.1158/1078-0432.CCR06-1059.

15. Sharifi MN, Mowers EE, Drake LE, Collier C, Chen H, Zamora M, Mui S, Macleod KF. Autophagy Promotes Focal Adhesion Disassembly and Cell Motility of Metastatic Tumor Cells through the Direct Interaction of Paxillin with LC3. Cell Rep. 2016; 15:1660-72. doi: 10.1016/j. celrep.2016.04.065.

16. Ezratty EJ, Partridge MA, Gundersen GG. Microtubuleinduced focal adhesion disassembly is mediated by dynamin and focal adhesion kinase. Nat Cell Biol. 2005; 7:581-90. doi: $10.1038 /$ ncb1262.

17. Mukhopadhyay A, Funato K, Stahl PD. Rab7 regulates transport from early to late endocytic compartments in Xenopus oocytes. J Biol Chem. 1997; 272:13055-9.

18. Gutierrez MG, Munafo DB, Beron W, Colombo MI. Rab7 is required for the normal progression of the autophagic pathway in mammalian cells. J Cell Sci. 2004; 117:2687-97. doi: $10.1242 /$ jes. 01114 .

19. Jager S, Bucci C, Tanida I, Ueno T, Kominami E, Saftig P, Eskelinen EL. Role for Rab7 in maturation of late autophagic vacuoles. J Cell Sci. 2004; 117:4837-48. doi: 10.1242/jcs.01370.

20. Mizushima N, Yoshimori T, Levine B. Methods in mammalian autophagy research. Cell. 2010; 140:313-26. doi: 10.1016/j.cell.2010.01.028.

21. Webb DJ, Donais K, Whitmore LA, Thomas SM, Turner CE, Parsons JT, Horwitz AF. FAK-Src signalling through paxillin, ERK and MLCK regulates adhesion disassembly. Nat Cell Biol. 2004; 6:154-61. doi: 10.1038/ ncb1094.

22. Xu Y, Bismar TA, Su J, Xu B, Kristiansen G, Varga Z, Teng L, Ingber DE, Mammoto A, Kumar R, Alaoui-Jamali MA. Filamin A regulates focal adhesion disassembly and suppresses breast cancer cell migration and invasion. J Exp Med. 2010; 207:2421-37. doi: 10.1084/jem.20100433.

23. Sandilands E, Serrels B, McEwan DG, Morton JP, Macagno JP, McLeod K, Stevens C, Brunton VG, Langdon WY, Vidal M, Sansom OJ, Dikic I, Wilkinson S, et al. Autophagic targeting of Src promotes cancer cell survival following reduced FAK signalling. Nat Cell Biol. 2012; 14:51-60. doi: 10.1038/ncb2386.

24. Salgia R, Sattler M, Pisick E, Li JL, Griffin JD. p210BCR/ $\mathrm{ABL}$ induces formation of complexes containing focal adhesion proteins and the protooncogene product $\mathrm{p} 120 \mathrm{c}-$ Cbl. Exp Hematol. 1996; 24:310-3.
25. Brown MC, Turner CE. Paxillin: adapting to change. Physiol Rev. 2004; 84:1315-39. doi: 10.1152/physrev.00002.2004.

26. Ballestrem C, Erez N, Kirchner J, Kam Z, Bershadsky A, Geiger B. Molecular mapping of tyrosine-phosphorylated proteins in focal adhesions using fluorescence resonance energy transfer. J Cell Sci. 2006; 119:866-75. doi: 10.1242/ jcs.02794.

27. Laukaitis CM, Webb DJ, Donais K, Horwitz AF. Differential dynamics of alpha 5 integrin, paxillin, and alpha-actinin during formation and disassembly of adhesions in migrating cells. J Cell Biol. 2001; 153:1427-40.

28. Burridge $\mathrm{K}$, Turner CE, Romer LH. Tyrosine phosphorylation of paxillin and pp125FAK accompanies cell adhesion to extracellular matrix: a role in cytoskeletal assembly. J Cell Biol. 1992; 119:893-903.

29. Turner CE, Schaller MD, Parsons JT. Tyrosine phosphorylation of the focal adhesion kinase pp125FAK during development: relation to paxillin. J Cell Sci. 1993; 105:637-45.

30. Schaller MD, Parsons JT. pp125FAK-dependent tyrosine phosphorylation of paxillin creates a high-affinity binding site for Crk. Mol Cell Biol. 1995; 15:2635-45.

31. Turner CE. Paxillin and focal adhesion signalling. Nat Cell Biol. 2000; 2:E231-6. doi: 10.1038/35046659.

32. Digman MA, Brown CM, Horwitz AR, Mantulin WW, Gratton E. Paxillin dynamics measured during adhesion assembly and disassembly by correlation spectroscopy. Biophys J. 2008; 94:2819-31. doi: 10.1529/ biophysj.107.104984.

33. West KA, Zhang H, Brown MC, Nikolopoulos SN, Riedy MC, Horwitz AF, Turner CE. The LD4 motif of paxillin regulates cell spreading and motility through an interaction with paxillin kinase linker (PKL). J Cell Biol. 2001; 154:161-76.

34. Pankov R, Cukierman E, Katz BZ, Matsumoto K, Lin DC, Lin S, Hahn C, Yamada KM. Integrin dynamics and matrix assembly: tensin-dependent translocation of alpha(5)beta(1) integrins promotes early fibronectin fibrillogenesis. J Cell Biol. 2000; 148:1075-90.

35. Zamir E, Katz M, Posen Y, Erez N, Yamada KM, Katz BZ, Lin S, Lin DC, Bershadsky A, Kam Z, Geiger B. Dynamics and segregation of cell-matrix adhesions in cultured fibroblasts. Nat Cell Biol. 2000; 2:191-6. doi: 10.1038/35008607.

36. Feng Y, He D, Yao Z, Klionsky DJ. The machinery of macroautophagy. Cell Res. 2014; 24:24-41. doi: 10.1038/ cr.2013.168.

37. Abou Zeid N, Valles AM, Boyer B. Serine phosphorylation regulates paxillin turnover during cell migration. Cell Commun Signal. 2006; 4:8. doi: 10.1186/1478-811X-4-8.

38. Tuloup-Minguez V, Hamai A, Greffard A, Nicolas V, Codogno P, Botti J. Autophagy modulates cell migration and beta1 integrin membrane recycling. Cell Cycle. 2013; 12:3317-28. doi: 10.4161/cc.26298. 
39. Zhan Z, Xie X, Cao H, Zhou X, Zhang XD, Fan H, Liu Z. Autophagy facilitates TLR4- and TLR3-triggered migration and invasion of lung cancer cells through the promotion of TRAF6 ubiquitination. Autophagy. 2014; 10:257-68. doi: 10.4161/auto.27162.

40. Zaidel-Bar R, Milo R, Kam Z, Geiger B. A paxillin tyrosine phosphorylation switch regulates the assembly and form of cell-matrix adhesions. J Cell Sci. 2007; 120:137-48. doi: 10.1242/jcs.03314.

41. Thomas JW, Cooley MA, Broome JM, Salgia R, Griffin JD, Lombardo CR, Schaller MD. The role of focal adhesion kinase binding in the regulation of tyrosine phosphorylation of paxillin. J Biol Chem. 1999; 274:36684-92.

42. Cecconi F. c-Cbl targets active Src for autophagy. Nat Cell Biol. 2012; 14:48-9. doi: 10.1038/ncb2413.

43. Kenific CM, Stehbens SJ, Goldsmith J, Leidal AM, Faure N, Ye J, Wittmann T, Debnath J. NBR1 enables autophagy-dependent focal adhesion turnover. J Cell Biol. 2016; 212:577-90. doi: 10.1083/jcb.201503075.

44. Rafiq K, Guo J, Vlasenko L, Guo X, Kolpakov MA, Sanjay A, Houser SR, Sabri A. c-Cbl ubiquitin ligase regulates focal adhesion protein turnover and myofibril degeneration induced by neutrophil protease cathepsin G. J Biol Chem. 2012; 287:5327-39. doi: 10.1074/jbc. M111.307009.

45. Bellis SL, Perrotta JA, Curtis MS, Turner CE. Adhesion of fibroblasts to fibronectin stimulates both serine and tyrosine phosphorylation of paxillin. Biochem J. 1997; 325: 375-81.

46. Didier C, Broday L, Bhoumik A, Israeli S, Takahashi S, Nakayama K, Thomas SM, Turner CE, Henderson S, Sabe H, Ronai Z. RNF5, a RING finger protein that regulates cell motility by targeting paxillin ubiquitination and altered localization. Mol Cell Biol. 2003; 23:5331-45.
47. Liu J, Kimura A, Baumann CA, Saltiel AR. APS facilitates c-Cbl tyrosine phosphorylation and GLUT4 translocation in response to insulin in 3T3-L1 adipocytes. Mol Cell Biol. 2002; 22:3599-609.

48. Madan R, Smolkin MB, Cocker R, Fayyad R, Oktay MH. Focal adhesion proteins as markers of malignant transformation and prognostic indicators in breast carcinoma. Hum Pathol. 2006; 37:9-15. doi: 10.1016/j. humpath.2005.09.024.

49. Cao QH, Liu F, Yang ZL, Fu XH, Yang ZH, Liu Q, Wang L, Wan XB, Fan XJ. Prognostic value of autophagy related proteins ULK1, Beclin 1, ATG3, ATG5, ATG7, ATG9, ATG10, ATG12, LC3B and p62/SQSTM1 in gastric cancer. Am J Transl Res. 2016; 8:3831-47.

50. Arboleda MJ, Lyons JF, Kabbinavar FF, Bray MR, Snow BE, Ayala R, Danino M, Karlan BY, Slamon DJ. Overexpression of AKT2/protein kinase Bbeta leads to up-regulation of betal integrins, increased invasion, and metastasis of human breast and ovarian cancer cells. Cancer Res. 2003; 63:196-206.

51. Benlimame N, He Q, Jie S, Xiao D, Xu YJ, Loignon M, Schlaepfer DD, Alaoui-Jamali MA. FAK signaling is critical for ErbB-2/ErbB-3 receptor cooperation for oncogenic transformation and invasion. J Cell Biol. 2005; 171:505-16. doi: 10.1083/jcb.200504124.

52. Alaoui-Jamali MA, Bismar TA, Gupta A, Szarek WA, Su J, Song W, Xu Y, Xu B, Liu G, Vlahakis JZ, Roman G, Jiao J, Schipper HM. A novel experimental heme oxygenase-1targeted therapy for hormone-refractory prostate cancer. Cancer Res. 2009; 69:8017-24. doi: 10.1158/0008-5472. CAN-09-0419. 